\title{
Frankfurter Dermatologentagung - 11. November 2015, Klinik für Dermatologie, Venerologie und Allergologie, Universitätsklinikum der Johann Wolfgang Goethe-Universität, Frankfurt am Main
}

\author{
Annual Frankfurt Dermatology Meeting \\ November 11, 2015, Department of Dermatology and Allergology \\ Johann Wolfgang Goethe-University Frankfurt, Main
}

Autoren

Institut

\section{A. Pinter, M. Wolter, R. Kaufmann}

Klinik für Dermatologie, Venerologie und Allergologie, Universitätsklinikum Frankfurt am Main
Bibliografie

Dol http://dx.doi.org/

10.1055/s-0041-107769

Akt Dermatol 2015; 41: 537-555

(c) Georg Thieme Verlag KG

Stuttgart · New York

ISSN 0340-2541

Korrespondenzadresse Dr. med. Andreas Pinter Klinik für Dermatologie, Venerologie und Allergologie Johann Wolfgang GoetheUniversität

Theodor-Stern-Kai 7 60590 Frankfurt am Main andreas.pinter@kgu.de 17-monatiges Kind mit „blauen Flecken“ Infantiles, akutes, hämorrhagisches Ödem (Seidlmayersche Kokardenpurpura)

\section{A. Messerschmidt}

Anamnese: Die Mutter des 17 Monate alten, männlichen Patienten berichtete, dass wenige Stunden vor Erstvorstellung in der Ambulanz an beiden Armen und Beinen erstmalig spontan gerötete Schwellungen auftraten ( $\boldsymbol{A}$ Abb.1). Es bestanden weder Schmerzen, Juckreiz noch Fieber oder eine Verschlechterung des Allgemeinzustandes. Anamnestisch sei das Kind sonst immer gesund gewesen.

Untersuchungsbefund: An den Streckseiten der Extremitäten zeigten sich disseminiert verteilte, livid-erythematöse, teils konfluierend-kokardenartige, bis mehrere Zentimeter durchmessende, ödematös-hämorrhagische Plaques. Das übrige Integument stellte sich altersentsprechend regelrecht dar.

Histologie: Es fand sich eine die gesamte Dermis durchsetzende interstitielle, ödematöse Entzündungsreaktion mit neutrophilen und eosinophilen Granulozyten. Fokal fielen nur einzelne frische Hämorrhagien auf ( $\bullet$ Abb.2).

Diagnose: In Zusammenschau von Klinik und histologischem Befund stellten wir die Diagnose eines infantilen, akuten, hämorrhagischen Ödems. Differenzialdiagnosen wie traumatische Hämatome und ein Erythema exsudativum multiforme sowie ein malignes Geschehen (z.B. Lymphom) konnten durch den klinischen und histologischen Befund ausgeschlossen werden.

Verlauf: Ohne jede Therapie waren die Hautveränderungen innerhalb einer Woche nahezu komplett abgeheilt. Ein möglicher Auslöser wie zum Beispiel Infekte oder Medikamente konnte bei unserem kleinen Patienten nicht gefunden werden. Kommentar: Beim infantilen, akuten, hämorrhagischen Ödem (Seidlmayersche Kokardenpur-

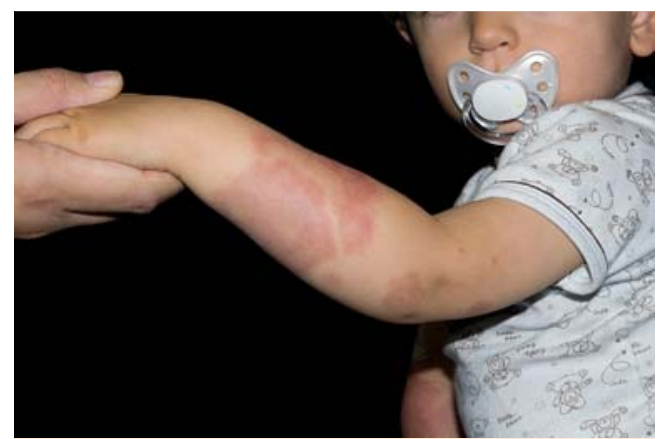

Abb.1 Linker Unterarm des jungen Patienten mit dem hämorrhagischen Ödem im akuten Zustand.

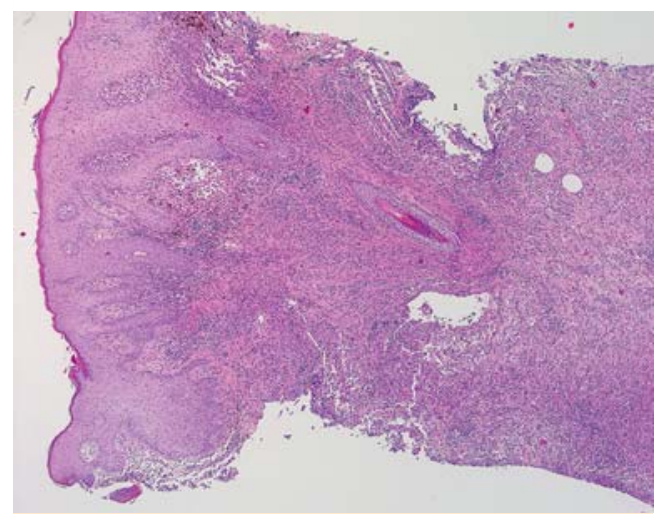

Abb.2 Interstitielle, ödematöse Entzündungsreaktion sowie vereinzelte Hämorrhagien in der oberen Dermis (HE 40x).

pura) handelt es sich um eine leukozytoklastische Vaskulitis, die ausschließlich die Haut betrifft und spontan abheilt. Bis 2007 waren weltweit zirka 300 Fälle der Erkrankung beschrieben worden. 80\% der Patienten waren bei Diagnosestellung zwischen 6 und 24 Monaten alt. Jungen sind doppelt so häufig betroffen wie Mädchen. In 70\% der Fälle geht der Erkrankung ein Infekt (Atemwegsinfekt, Diarrhoe oder Harnwegsinfekt) voraus. Laborkontrollen sind in der Regel nicht wegweisend. 
Die Hautveränderungen entstehen typischerweise rasch und umfassen meist große, rund bis ovale, livid-erythematöse Urticae an Wangen, Ohren und Extremitäten. Oft treten kokardenartige Läsionen und Ödeme der distalen Extremitäten auf. Andere Organe werden in der Regel nicht befallen. Die Hautveränderungen heilen innerhalb von 2 bis 60 Tagen spontan ab. Eine effektive medikamentöse Therapie ist nicht bekannt, systemische Steroide haben keinen Einfluss auf den Krankheitsverlauf. Wichtig ist, die Krankheit zu kennen und die Angehörigen über das selbstlimitierende, harmlose Krankheitsbild aufzuklären.

\section{Literatur}

1 Fiore E, Rizzi M, Simonetti GD et al. Acute hemorrhagic edema of young children: a concise narrative review. Eur J Pediatr 2011; 170: 1507 1511

2 Karremann M, Jordan AJ, Bell $N$ et al. Acute hemorrhagic edema of infancy: report of 4 cases and review of the current literature. Clin Pediatr (Phila) 2009; 48: 323-326

\section{Chronische Ulzeration im zentrofazialen Gesicht - das Ulcus trophoneuroticum}

\section{R. Schlosser}

\section{Fall 1}

Anamnese: Uns wurde ein 58-jähriger Mann aus der Hals-NasenOhren-Klinik überwiesen, der seit etwa sieben Monaten über Schmerzen im Bereich des linken Nasenflügels klagte. Im Verlauf von vier Monaten habe sich am Nasenflügel eine „Wunde“ gebildet. Auf Nachfragen gibt der Patient an, dass er sich auch regelmäßig an die schmerzende Hautstelle fasse. Unter den Vorerkrankungen sind neben einem Diabetes mellitus Typ II auch bereits vier Schlaganfälle zu vermerken.

Befund: Ein zirka $3 \mathrm{~cm}$ im Durchmesser großes, mutilierendes Ulkus präsentiert sich am linken Nasenflügel - das Nasenseptum liegt zwar frei, ist aber nicht beeinträchtigt. Das umliegende Gewebe scheint hingegen unauffällig ( $\bullet$ Abb.3).

Diagnostik: Histologisch erkennt man dysplasiefreies Plattenepithel teils mit Verhornung, papillomatös konfiguriert. Weiterhin zeigt sich Übergangsepithel und Anteile einer flächigen Ulzeration. Diese reichen bis auf den hier miterfassten Knorpel. Im Bereich des tiefen Granulationsgewebes sind auch immer wieder einzelne glandulär imponierende Strukturen mit regeneratorischer Epithelveränderung vorhanden. Darüber hinaus ergibt sich kein Anhalt auf Malignität. Zusammenfassend zeigte die Histologie eine herdförmig floride, ulzeröse und granulierende Entzündung sowie regeneratorische Epithelveränderungen.

\section{Fall 2}

Anamnese: Es stellt sich ein 77-jähriger Mann vor, der seit einigen Jahren eine nicht heilende Wunde neben der Nase rechts festgestellt habe. Die Ehefrau berichtet, dass er auch häufig „die Finger im Gesicht habe“. In der Vorgeschichte ließ sich ein Schlaganfall durch ein Wallenberg-Syndrom eruieren, weiterhin ein Diabetes mellitus und eine gemischte Hyperlipidämie.

Befund: Es zeigte sich ein ulzerierter Defekt von etwa $2,5 \times 1 \mathrm{~cm}$ rechtsseitig lateral der Nase mit Destruktion des Nasenflügels. Weiterhin präsentierten sich eine Ulzerationen von $2 \times 0,5 \mathrm{~cm}$ entlang der rechten Nasolabialfalte und zwei, nur oberflächlicherosive Läsionen am Kinn $(\bullet$ Abb.4).

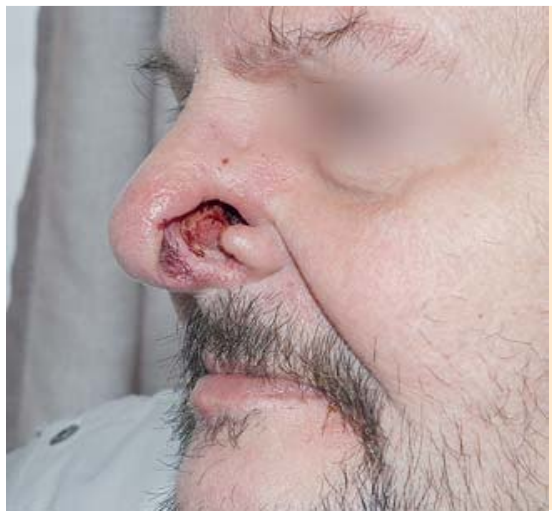

Abb.3 Patient 1: Destruierender Defekt des linken Nasenflügels ohne weitere Zeichen einer Inflammation oder eines Tumors.

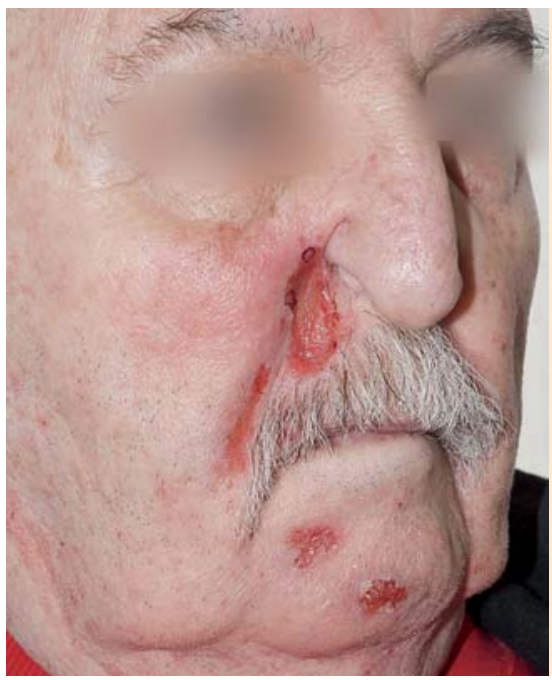

Abb.4 Patient 2: Hautbefund mit Destruktion des rechten Nasenflügels sowie weiteren Ulzerationen und Exkoriationen nasolabial und perioral rechtsseitig.

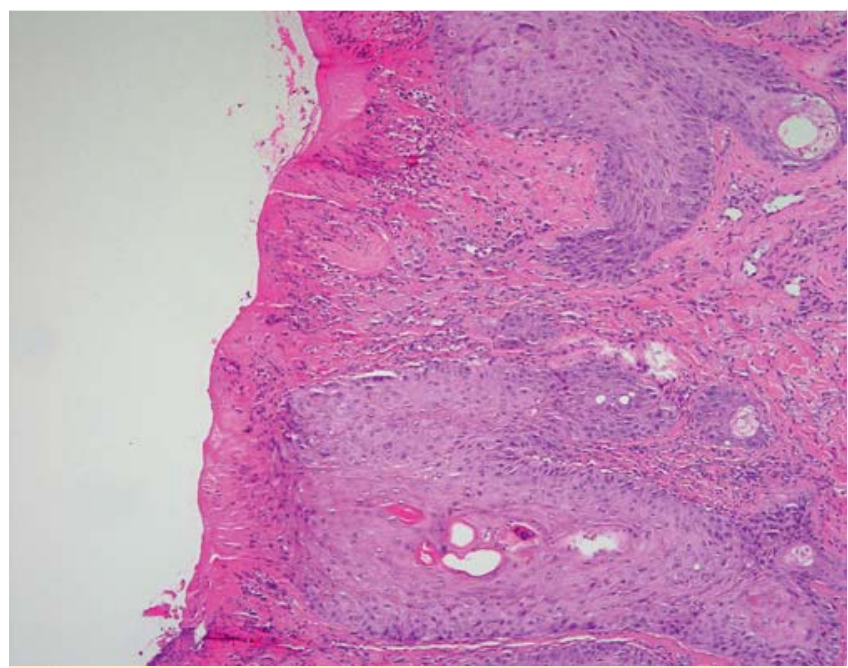

Abb.5 Histologie: Parakeratotisch verhornendes Oberflächenepithel mit erodierter Gewebsvermehrung im Sinne einer reaktiven Epidermishyperplasie (HE $100 \times)$.

Diagnostik: In der Übersicht der Histologie zeigten sich eine angedeutet parakeratotisch-verhornende und oberflächlich erodierte Gewebevermehrung sowie kompakte Formationen pleomorpher Keratinozyten, welche noch in Verbindung zur Epidermis und den Follikelstrukturen stehen. Eingestreut waren Einzelzellverhornungen zu erkennen. Zusammenfassend beurteilt als reaktive Epidermishyperplasie ohne Anhalt für Malignität $($ Abb.5). 
Diagnose: Aufgrund der klinischen Befunde in Zusammenschau mit den neurologischen Grunderkrankungen stellten wir bei beiden Patienten die Diagnose eines Ulcus trophoneuroticum.

Therapie: Wir empfahlen die konsequente Unterlassung der Manipulation, Fucidine-Creme und Vorstellung bei den Kollegen der Neurologie zur Therapie mit Antidepressiva. Eine operative Rekonstruktion des Befundes wurde von beiden Patienten zunächst verweigert.

Kommentar: Das Ulcus trophoneuroticum (UT) tritt als Folge einer Nervenschädigung des Nervus trigeminus auf und stellt ein sehr seltenes Krankheitsbild dar. In einer Literaturzusammenfassung aus dem Jahr 2014 wurden bis dahin nur 60 beschriebene Fälle zusammengefasst. Zugrunde liegt dem UT am häufigsten eine iatrogene Schädigung des Nervus trigeminus durch Operationen oder eine neurologische Erkrankung wie beispielsweise ein Schlaganfall. Charakteristisch ist ein ulzerierender Defekt am Nasenflügel kombiniert mit Parästhesien im betroffenen Gebiet. Meist geben die Patienten oder Angehörigen auf Nachfragen ein häufiges Berühren oder Kratzen des betroffenen Areals an. Das UT tritt vermehrt rechtsseitig auf - eine kausale Erklärung hierfür wurde bis dato nicht gefunden. Fast ausschließlich ist das Innervationsgebiet des Nervus maxillaris von diesem ungewöhnlichen Krankheitsbild betroffen, seltener die beiden anderen Trigeminusäste. Die Behandlung des UT kann unter Umständen eine Herausforderung darstellen. Eine Fortführung der Manipulation sollte zunächst unbedingt verhindert werden. Unterstützend können hierbei ein stadiengerechtes Wundmanagement und Antidepressiva wie Carbamazepin und Gabapentin wirken. Unter Antidepressiva verbessern sich häufig die Missempfindungen in den betroffenen Arealen. Bei ausgedehnten Defekten kann eine operative Rekonstruktion sinnvoll sein - allerdings sind Rezidivraten von mehr als $50 \%$ beschrieben. Zusammenfassend ist der Therapieverlauf oft langwierig und kann sowohl für Patienten als auch Arzt frustrierend sein.

\section{Literatur}

1 Sawada T, Asai J, Nomiyama $T$ et al. Trigeminal trophic syndrome: report of a case and review of the published work. J Dermatol 2014; 41: $525-528$

2 Rashid RM, Khachemoune A. Trigeminal trophic syndrome. J Eur Acad Dermatol Venereol 2007; 21: 725-731

3 Garza I. The trigeminal trophic syndrome: an unusual cause of face pain, dysesthesias, anaesthesia and skin/soft tissue lesions. Cephalalgia 2008; 28: 980-985

\section{Irreversible Alopezie und Nagelveränderungen durch Taxane \\ $\nabla$}

\section{K. Schultheis}

Anamnese: Die Vorstellung der 53-jährigen Patientin erfolgte aufgrund von Haarverlust, Wachstumsstörungen des Haars sowie Nagelveränderungen nach einer Therapie mit Paclitaxel (insgesamt 18 Zyklen $80 \mathrm{mg} / \mathrm{m}^{2} \mathrm{KOF}$ ) aufgrund eines metastasierten Mammakarzinoms. Die letzte Gabe von Paclitaxel erfolgte vor mehr als sechs Monaten. Ein vermehrtes Haarwachstum wurde jedoch nach Beendigung der Therapie nicht verzeichnet.

Untersuchungsbefund: An der Kopfhaut findet sich eine diffuse, nicht vernarbende Alopezie mit Verlust von mehr als 50\% der Kopfbehaarung ( $\bullet$ Abb. $\mathbf{6})$. Zusätzliche Rarefizierung der Augenbrauen sowie der genitalen und axillären Behaarung. An Hand-

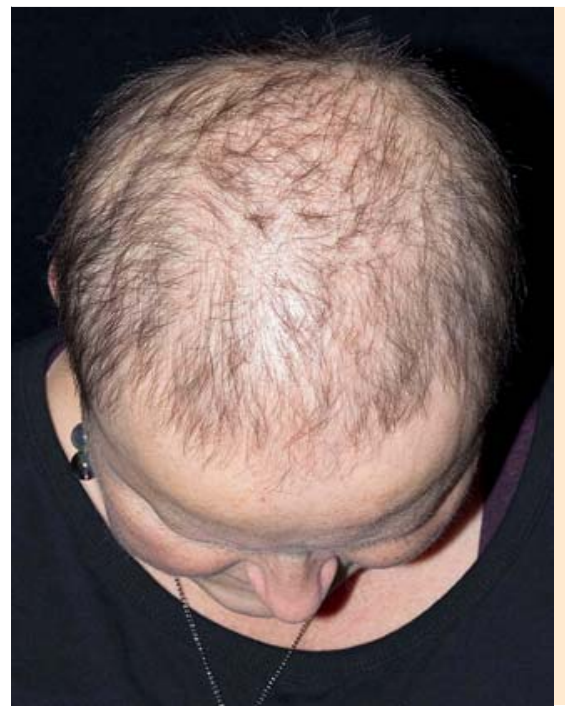

Abb. 6 Kopf: Deutliches Effluvium des temporalen, parietalen und hochokzipitalen Kapillitiums.

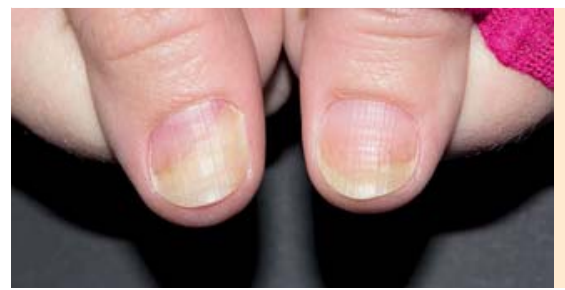

Abb.7 Nägel:

Distale Onycholyse der Digiti I beider Hände.

und Fußnägeln zeigt sich eine Onycholyse am distalen Anteil (๑ Abb.7).

Therapie und Verlauf: Wir klärten die Patientin über das Vorhandensein einer möglichen irreversiblen Haar- und Nagelwachstumsstörung nach Therapie mit Taxanen auf. Auf weitere Diagnostik wurde bei eindeutiger Klinik verzichtet. Das Tragen einer Perücke lehnte die Patientin ab. Es erfolgte die Einleitung eines Therapieversuches mit Minoxidil 2\% Schaum zweimal täglich. Nach einem dreimonatigen Kontrolltermin zeigte sich hierunter jedoch kein Ansprechen.

Kommentar: Paclitaxel gehört zu der Gruppe der Taxane und wurde früher aus Blättern der pazifischen Eibe (lat.: Taxus) gewonnen. Taxane werden zur Behandlung von verschiedenen solitären Krebsarten (Mammakarzinom, malignes Melanom, nicht-kleinzelliges Bronchialkarzinom oder Ovarilkarzinom) eingesetzt. Durch Störung des Mikrotubuli-Netzwerks und Hemmung der Angiogenese kommt es zur Unterdrückung der Mitose - Tumorzellen gehen daher in Apoptose. Bekannte Nebenwirkungen sind Knochenmarksdepression, Polyneuropathie, Übelkeit und Erbrechen sowie eine normalerweise reversible Alopezie. Das Besondere an unserem Fall ist die anhaltende Alopezie. Bisher sind nur einzelne Fälle einer irreversiblen Alopezie unter einer Chemotherapie mit Taxanen beschrieben. Es gibt zwei verschiedene Arten von Chemotherapie-induzierter Alopezie, nämlich das telogene und das anagene Effluvium. Bei der telogenen Alopezie (z. B. durch 5-Fluoruracil erzeugt) wechseln mehr Haare als normalerweise von der anagenen in die telogene Phase. Hier sind meistens nicht mehr als 50\% der Haare betroffen. Der Haarausfall wird subjektiv nur von den Patienten selbst bemerkt und tritt erst 3-4 Monate nach der ersten Gabe auf.

Bei dem anagenen Effluvium (Taxane, Cyclophosphamid) greifen die Chemotherapeutika die schnell teilenden Haarmatrixzellen in der Anagenphase an. Hierdurch kommt es zu deutlich stärke- 
rem Haarverlust. Bereits 2-3 Wochen nach der ersten Gabe kommt es zu einem raschen, deutlich sichtbaren Haarausfall. Die Alopezie ist psychisch sehr belastend für die Patienten. Als eine vorbeugende Möglichkeit wurde eine iatrogen induzierte Hypothermie während der Chemotherapiebehandlung beschrieben. Hierdurch soll es zur Minderperfusion des Skalps kommen somit gelangt weniger Chemotherapeutikum in die Haarfollikel. Der dadurch zu erwartende Effekt ist aber eher gering. Minoxidil $2 \%$ lokal aufgetragen bringt prophylaktisch nichts, kann aber unter Umständen das Haarwachstum nach der Therapie fördern. Die Wirksamkeit von anderen Therapieoptionen (wie z.B. Vitamin D3, Vitamin E) konnte in Studien nicht bewiesen werden.

Die Chemotherapie-induzierte Alopezie ist psychisch sehr belastend für die Patienten, da das Haar viel zur äußerlichen Persönlichkeit beiträgt. Bei der Aufklärung sollte auch über den seltenen Fall einer irreversiblen Alopezie berichtet werden.

\section{Literatur}

1 Yeager CE, Olsen EA. Treatment of chemotherapy-induced alopecia. Dermatologic Therapy 2011; 24: 432-442

2 Tallon B, Blanchard E, Goldberg LJ. Permanent chemotherapy-induced alopecia: a case report and review of the literature. J Am Acad Dermatol 2010; 63: 333-336

3 Friedrichs K, Carstensen MH. Successful reduction of alopecia induced by anthracycline and taxane containing adjuvant chemotherapy in breast cancer - clinical evaluation of sensor-controlled scalp cooling. Springerplus 2014; 3: 500

\section{Livedovaskulopathie mit fulminantem Verlauf - gestrecktes Kokain als möglicher Auslöser}

\section{Hrgovic}

Anamnese: Wir berichten über eine 28 -jährige Patientin mit seit zirka zehn Monaten bestehenden, größenprogredienten und schmerzhaften Ulzerationen an beiden Unterschenkeln. Als relevante Nebendiagnose besteht seit dem 18. Lebensjahr ein inhalativer Kokainabusus. Es wurden von der Patientin keine weiteren Erkrankungen und Medikamenteneinnahmen angegeben.

Untersuchungsbefund: An beiden Beinen zeigten sich netzförmig-marmorierte, bräunlich-rote Maculae im Sinne eines Livedobildes. Weiterhin fanden sich an den Dorsalseiten der unteren Extremitäten etwa münzgroße, konfluierende, mit hämorrhagischen Krusten bedeckte Ulzerationen ( $\bullet$ Abb.8).

Diagnostik: Die Labordiagnostik ergab leicht erhöhte Entzündungsparameter, eine ausgeprägte Anämie und Leukopenie. In den serologischen Untersuchungen sind positive antinukleäre Antikörper (ANA), perinukleäre und cytoplasmatische-Anti-Neutrophile cytoplasmatische Antikörper (p/c-ANCA) aufgefallen. Es erfolgte eine Probebiopsie der Hautveränderungen. Hier konnten zahlreiche Alterationen im Bereich der Gefäße mit Hinweisen auf stattgehabte Okklusionen und Rekanalisationen nachgewiesen werden. Weiterhin kamen multiple, stellenweise okkludierte, mikrothrombosierte Gefäße zur Ansicht ( Abb.9). Die Thrombophiliediagnostik war unauffällig. In Zusammenschau der Befunde wurde die Diagnose einer Livedovaskulopathie gestellt.

Therapie und Verlauf: Unter einer Glukokortikoidtherapie ( $2 \mathrm{mg} /$ $\mathrm{kg}$ Prednisolonäquivalent), Antikoagulation mit niedermolekularem Heparin (NMH) und stadiengerechter Wundbehandlung kam es innerhalb von 3 Wochen zu einer deutlichen Besserung der Hautbefunde. Die immunsuppressive Therapie wurde initial zur Langzeitbehandlung auf Azathioprin $(2 \times 50 \mathrm{mg} / \mathrm{d})$ umgestellt.

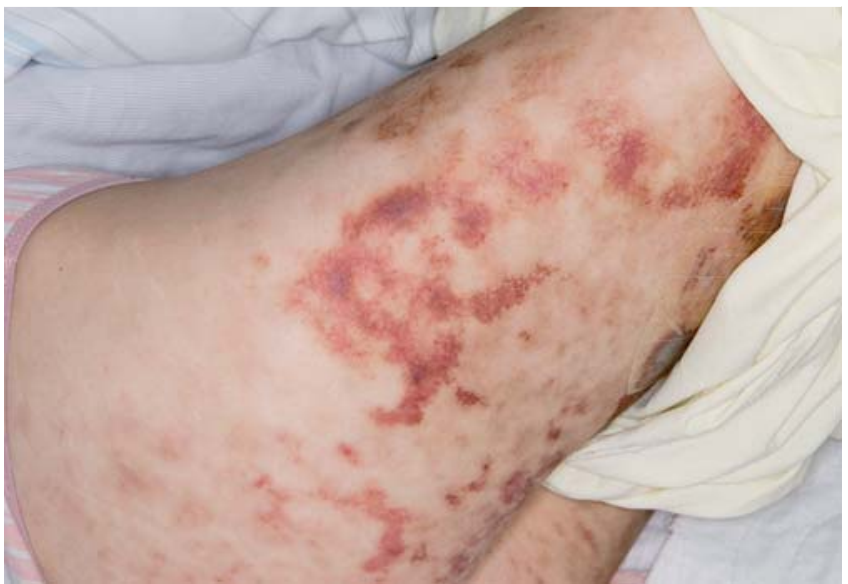

Abb.8 Oberschenkelaußenseite mit teils konfluierenden, netzförmigmarmorierten, rotbraunen Maculae als klassisches, klinisches Bild einer Livedovaskulitis.

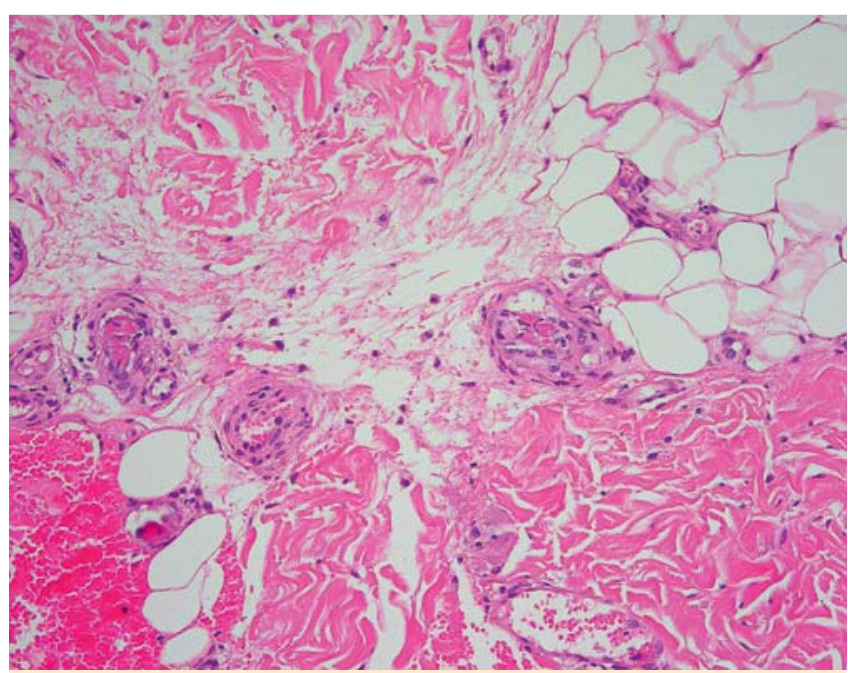

Abb.9 Histologie: Dermis mit frischer Mikrothrombose, bestehender Okklusion und Rekanalisationen der Lumen (HE 40×).

Die Patientin wurde darauf hingewiesen sich einem Drogenentzug zu unterziehen, um eine längerfristige Verbesserung der Hautbefunde zu erzielen. Leider ist die Patientin der Empfehlung nicht nachgekommen. Wegen rezidivierender Ulzerationen bei weiterhin bestehendem Kokainkonsum wurde unsere Patientin innerhalb von fünf Jahren insgesamt sechsmal stationär behandelt. Unter systemischer Glukokortikoidtherapie, Antikoagulation mit NMH und intensivierten Lokalbehandlungen kam es dabei immer wieder zu einer Verbesserung des Hautbildes. Letztmalig stellte sich die Patientin notfallmäßig im Frühjahr 2015 mit dramatischen Lokalbefunden in unserer Ambulanz vor. Es fanden sich großflächige, tiefreichende Nekrosen an beiden dorsalen Oberschenkeln und am Gesäß ( $\bullet$ Abb. 10). Zur weiteren Behandlung wurde die Patientin in eine externe plastisch-chirurgische Abteilung verlegt. Nach operativem Débridement mit Nekrosektomie unter Fortführung der immunsuppressiven Therapie mit Methylprednisolon sowie Plasmapherese wurden die Defekte nach VAC-Therapie mittels Spalthauttransplantaten gedeckt. Aufgrund von neuen lividen Hautveränderungen wurde die immunsuppressive Therapie um Endoxan erweitert. Mit deutlich gebesserten Hautbefunden konnte die Patientin schließlich zur weiteren Rehabilitation entlassen werden. 


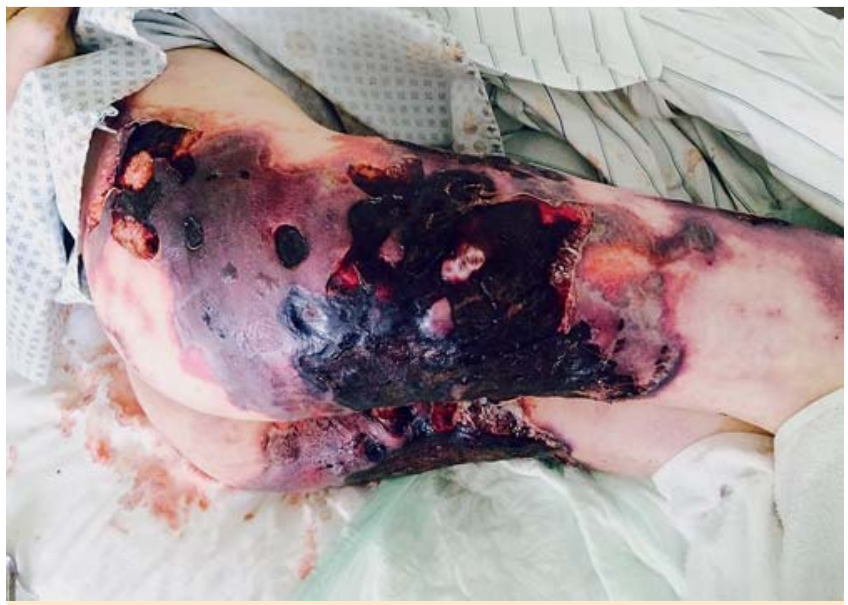

Abb.10 Fulminanter Verlauf der Livedovaskulitis mit großflächiger Nekrotisierung des Gesäßes und der dorsalen Oberschenkel.

Kommentar: Die Livedovaskulopathie ist eine thrombo-embolische Verschlusskrankheit des kutanen Gefäßplexus und wird charakterisiert durch das rezidivierende Auftreten von schmerzhaften Ulzerationen der unteren Extremitäten. Die Inzidenz liegt für den deutschsprachigen Raum schätzungsweise bei 1/100000 und erfüllt damit die Kriterien für eine „orphan disease“. Die Erkrankung betrifft vorwiegend das weibliche Geschlecht (>75\%). Klinisch ist die Livedovaskulopathie durch die Trias Livedo racemosa, Ulzerationen und Atrophie blanche gekennzeichnet, wobei nicht alle drei Charakteristika zusammen auftreten müssen. Am Integument manifestiert sich die Erkrankung primär an den unteren Extremitäten, kann aber auch andere Regionen befallen. Charakteristisch für die Diagnose einer Livedovaskulopathie ist der histologische Nachweis von thrombotisch okkludierten Gefäßen in der mittleren und tiefen Dermis.

Der Pathomechanismus ist noch nicht vollständig aufgeklärt. Als gesichert gilt, dass eine abnorme Gerinnungsaktivität die Bildung von dermalen Mikrothromben begünstigt. Verschiedene prothrombotische Faktoren sind daher mit dem Krankheitsbild assoziiert (wie z.B. Kryoglobuline, Kälteagglutinine, ANAs, ANCAs, Protein C/S, Lupus-Antikoagulans). Als weiterer Risikofaktor für die Entstehung von gefäßbedingten Hautulzerationen gilt der Konsum von Kokain. Aufgrund der vasokonstriktorischen Wirkung kann Kokain Ulzerationen und Hautnekrosen auslösen. Insbesondere die Beimischung von Levamisol als Streckmittel zum Kokain gilt als potenzieller zusätzlicher Faktor für die Entwicklung einer Livedovaskulopathie. Levamisol ist ein Anthelmintikum aus der Tiermedizin und potenziert die Kokainwirkung um ein Vielfaches. In der Literatur wurden Fälle von Levamisol-induzierten Livedovaskulopathien beschrieben. Klinisch manifestieren sich die Livedo-typischen Erytheme und Ulzerationen am Gesicht und den unteren Extremitäten. Typischerweise gehen diese Veränderungen mit einer Leukopenie und der Bildung von Autoantikörpern (insbesondere ANAs und ANCAs) einher. Eine begleitende immunsuppressive Therapie bei ANA/ANCA-assoziierter Livedovaskulopathie scheint den Therapieverlauf zu begünstigen. Die erfolgreiche Behandlung in Kokain/Levamisolinduzierten Fällen ist allerdings an eine strikte Drogenabstinenz gekoppelt.

\section{Literatur}

1 Goerge T. Livedovaskulopathie, Pathogenese, Diagnostik und Therapie des Hautinfarkts. Hautarzt 2011; 62: 627-634

2 Shawwa K, Alraiyes AH, Eisa $\mathrm{N}$ et al. Cocaine-induced leg ulceration. BMJ Case Rep 2013; pii: bcr2013200507

3 Crowe DR, Kim PS, Mutasim DF. Clinical, histopathologic, and immunofluorescence findings in levamisole/cocaine-induced thrombotic vasculitis. Int J Dermatol 2014; 53: 635-637

\section{Pili trianguli et canaliculi - Syndrom der unkämm- baren Haare}

\section{W. Hofmann}

Anamnese: Ein 3-jähriger Junge stellte sich mit zunehmend „strohigen“ Haaren vor. Im Säuglingsalter bestanden hingegen noch lockige, deutlich weichere Haare. Vor Beginn der Haarveränderungen wurde eine kurze Episode mit Juckreiz und verstärktem Haarausfall beschrieben. Die Familienanamnese bezüglich Haaranomalien zeigt sich unauffällig.

Im ersten Lebensjahr erfolgte eine Sagittalnaht-Synostose-Operation. Zudem war eine Chondrodysplasia punctata durch X-chromosomale Deletion des ARSE (Arylsulfatase E)-Gens mit resultierenden Asymmetrien der körperlichen Proportionen sowie eine Mutation im SHOX (Short Stature Homeobox)-Gen mit resultierendem Minderwuchs bekannt. Die restliche kindliche Entwicklung verlief normal. Die Zwillingsschwester hat die gleichen Gendefekte, aufgrund X-chromosomalem Erbgang in deutlich schwächerer Ausprägung. Bei ihr sind bislang keine Haaranomalien auffällig.

Untersuchungsbefund: Es finden sich ubiquitär blonde, abstehende, nicht kämmbare Haare ( $\bullet$ Abb.11). Kopfhaut, Zähne, Nägel und das restliche Integument zeigen keine Veränderungen. Es bestehen Auffälligkeiten der körperlichen Proportionen u.a. Hypertelorismus, Retrogenie, prominente Stirn, sehr schmale Oberlippe sowie kurze Beine im Verhältnis zum langen Oberkörper.

Kommentar: Klinisch wurde die Diagnose des Syndroms der unkämmbaren Haare, auch als Pili trianguli et canaliculi oder Uncombable Hair Syndrome bezeichnet, gestellt. Das Syndrom der unkämmbaren Haare ist eine seltene Haarschaftanomalie, gekennzeichnet durch krause, widerspenstige Haare, die nicht flach auf der Kopfhaut aufliegen, sodass ein Kämmen nahezu unmöglich ist. Die Diagnose wird durch den lichtmikroskopischen Nachweis des dreieckigen Haarschafts (Pili trianguli) mit längsgezoge-

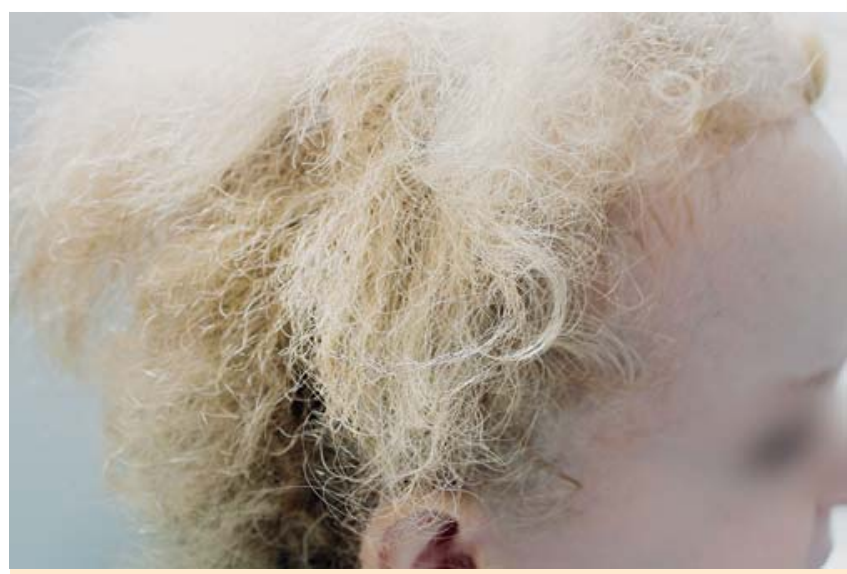

Abb.11 Unkämmbare „strohige“ Kopfhaare des 3-jährigen Jungen. 


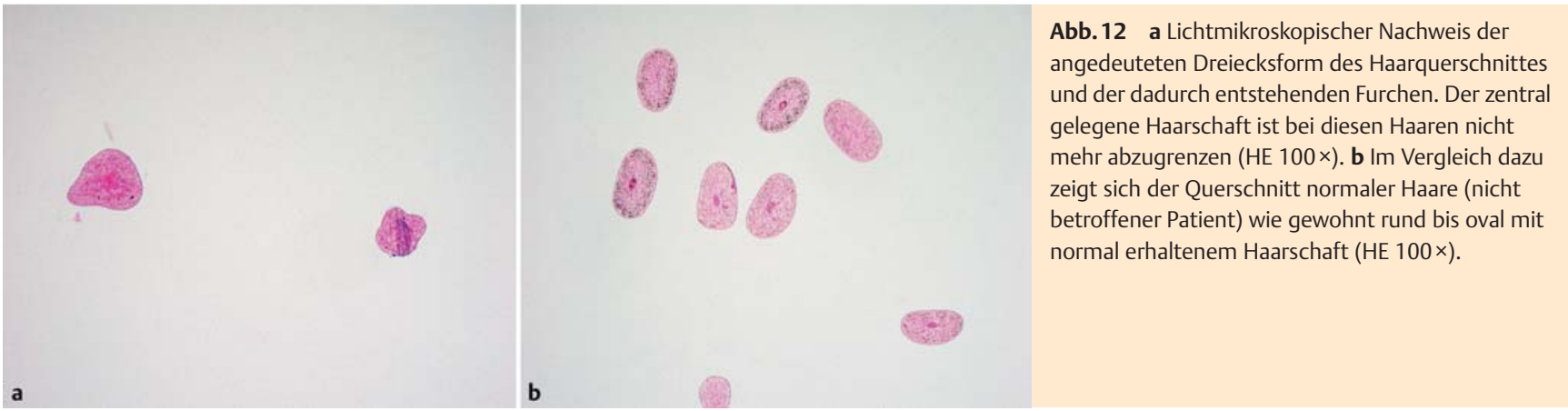

nen Furchen (et canaliculi) gestellt ( $\bullet$ Abb.12a und b). Einige Fälle treten autosomal dominant, andere sporadisch auf. Eine genaue Ursache ist bislang nicht bekannt. In seltenen Fällen sind Assoziationen zu ektodermalen Dysplasien beschrieben. Insbesondere scheinen aber die bei unserem Patienten nachgewiesenen SHOX- und ARGE-Genmutationen nicht assoziiert zu sein. Oben aufgelistete Auffälligkeiten der körperlichen Proportionen resultieren aus dem ARSE-Genverlust, der eine brachytelephalange Chondrodysplasia punctata zur Folge hat, bei der es zu einer Wachstumsstörung infolge einer Skelettdysplasie kommt. Nach der vorliegenden Fachliteratur bessert sich das nicht kämmbare, widerspenstige Haarbild bis zur Pubertät. Eine kausale Therapie ist nicht bekannt. Symptomatische Therapien (z. B. Conditioner) können versucht werden. In Einzelfällen wurde berichtet, dass mit Biotin $5 \mathrm{mg} / \mathrm{d}$ eine Besserung des Haarbildes nach zwei Jahren erreicht werden konnte. Ansonsten gilt, den gutartigen Verlauf abzuwarten.

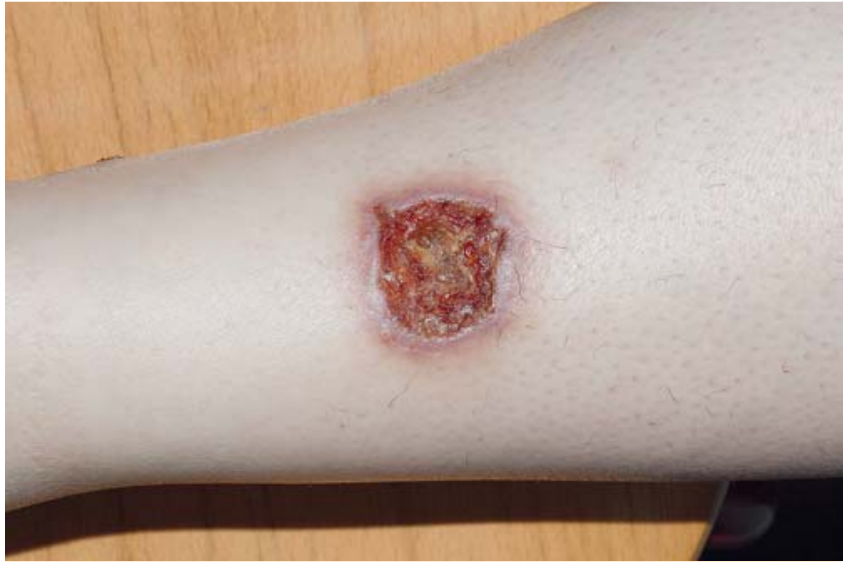

Abb.13 Mit hämorrhagischer Kruste bedecktes Ulkus, umrandet von einem lividroten, leicht plaqueartigen Saum am linken Unterschenkel.

\section{Literatur}

1 Calderon P, Otberg N, Shapiro J. Uncombable hair syndrome. J Am Acad Dermatol 2009; 61: 512-515

2 Boccaletti V, Zendri E, Giordano $G$ et al. Familial uncombable hair syndrome: ultrastructural hair study and response to biotin. Pediatr Dermatol 2007; 24: E14-E16

\section{Kutane Leishmaniose durch Leishmania major $\nabla$}

G. Hauck

Anamnese: Es präsentierte sich eine 44-jährige Patientin, die im Oktober 2014 im Libanon von einem unbekannten Insekt dreimal am Unterschenkel gestochen wurde. Daraufhin entstanden stark juckende Papeln, die von der Patientin regelmäßig aufgekratzt wurden und später zu nässen begannen. Fieber oder Schüttelfrost bestanden zu keiner Zeit, leichte Schmerzen seien jedoch vorwiegend nachts vorhanden gewesen.

Untersuchungsbefund: Es finden sich am linken Unterschenkel über dem medialen Malleolus sowie über der Tibia drei etwa jeweils $5-7 \mathrm{~cm}$ durchmessende Plaques, von denen zwei zentral eine mit hämorrhagischer Kruste bedeckte Ulzeration aufweisen. Der Randsaum zeigt sich leicht erythematös und aufgeworfen.

(- Abb.13)

Diagnostik: Aus einer Probebiopsie entnommenes Gewebe wurde durch eine DNS-Analyse zur Sicherung des Nachweises von Leishmania (Ziel-Sequenz: Leishmanien-Kinetoplast kDNA/ITS1) untersucht. Die Sequenzierung der amplifizierten DNS konnte Leishmania major nachweisen. Die histopathologische Begutachtung zeigte weiterhin eine oberflächlich-hyperkeratotische Epi-

dermis, unterlagert teilweise von nekrotisierenden Bereichen mit einem umgebenden, stark entzündlichen Infiltrat aus Lymphozyten, Makrophagen und Plasmazellen. Auf einzelnen Ebenen fand sich subepidermal die Darstellung von kleinen, hellen Korpuskeln - dies entspricht den Leishmanien. Die Probebiopsie zeigte sich vereinbar mit dem histologischen Bild einer kutanen Leishmaniose ( $\bullet$ Abb.14, $\bullet$ Abb. 15). Im Wundabstrich aus dem Ulkusgrund konnte dagegen nur eine unspezifische bakterielle Begleitbesiedlung nachgewiesen werden. Auch in der Blutentnahme ergaben sich keine weiteren Auffälligkeiten.

Therapie und Verlauf: In unserer Ambulanz wurde bereits nach dem Nachweis einer Infektion mit Leishmania major eine sechswöchige Therapie mit Fluconazol durchgeführt. Hierunter kam es jedoch zu keiner Befundbesserung. Es folgte eine stationäre Aufnahme zur intensivierten, stadiengerechten Wundversorgung einer ambulant therapierefraktären kutanen Leishmaniose. Diese beinhaltete eine vorsichtige Kürettage der Ulzeration mit nachfolgender antiseptischer Behandlung. Der nicht ulzerierte Plaque wurde keratolytisch mit Clioquinol 1\% plus Salicylvaseline 3\% in Vaseline vorbehandelt. Die Wundversorgung der ulzerierten Läsionen erfolgte fortführend mit Hydrogel in Kombination mit einem Polyurethanschaumverband. Hierunter zeigte sich eine zunehmende Wundgranulation, sodass die Patientin bereits nach wenigen Tagen in die ambulante Betreuung entlassen werden konnte.

Kommentar: Die kutane Leishmaniose wurde erstmals von Cunningham 1885 in einer in Indien durchgeführten Studie beschrieben. Die Erkrankung ist eine durch Parasiten der Leishmanien spp. verursachte Infektionserkrankung und wird über die weibliche Sand- bzw. Schmetterlingsmücke übertragen. Die Leishmaniose 


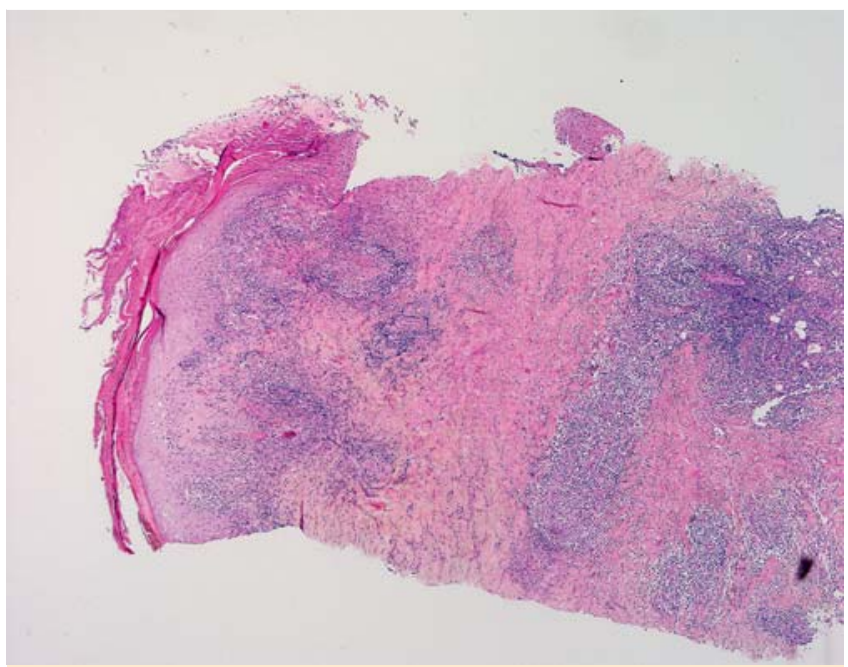

Abb. 14 Histologie - Übersicht: Oberflächlich-hyperkeratotische Epidermis mit nekrotisierenden Bereichen in der tiefen Dermis und einem entzündlichen Begleitinfiltrat (HE 40×).

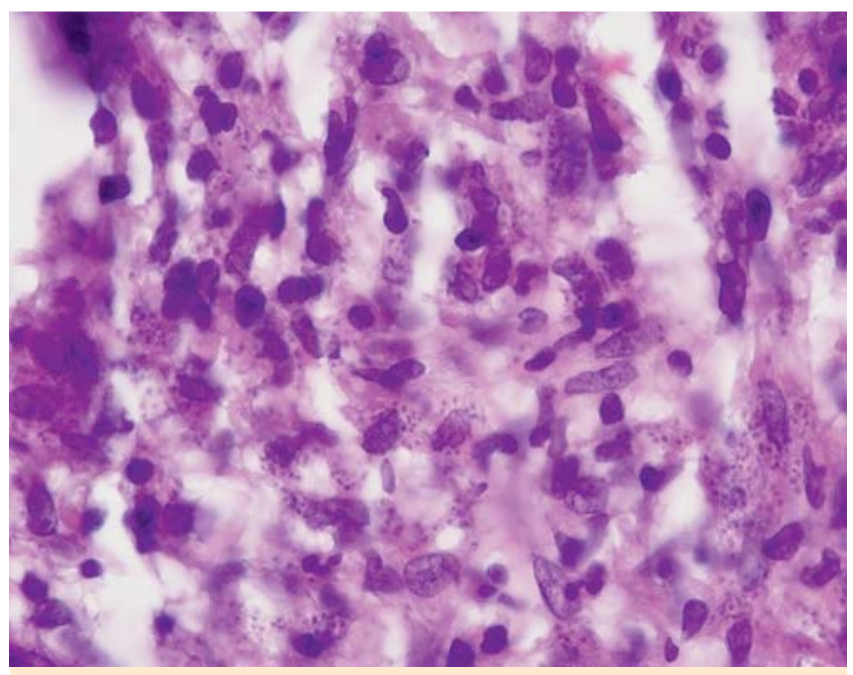

Abb. 15 Histologie - Detail: Nachweis der intrazellulären Leishmanien als dunklere, wie eingestreut wirkende Korpuskeln in den Fibroblasten der Dermis (HE 400 $\times$ ).

kann rein kutan, mukokutan oder viszeral ablaufen - mit variabler Klinik, abhängig von dem auslösenden Parasiten.

Zur Zeit sind etwa 15 verschiedene Spezies von Leishmanien bekannt. Eine klinisch relevante Einteilung der kutanen Form ist die Leishmaniose der „alten Welt“ (Afrika, Europa, Asien), die häufig harmlos verläuft und sogar selbstlimitierend sein kann. Dagegen kann die Leishmaniose der „neuen Welt“ (Süd- und Mittelamerika) deutlich aggressiver verlaufen und sollte immer therapiert werden.

Im Falle von L. major sollte bei anhaltendem Befund zunächst mittels Fluconazol $200 \mathrm{mg}$ tgl p.o. für mindestens sechs Wochen behandelt werden. Bei weiterer Therapierefraktivität kann ein Versuch mit einem Antimonpräparat (Pentostam) $20 \mathrm{mg} / \mathrm{kg} \mathrm{KG}$ i.m. begonnen werden. Antimonpräparate sind in Deutschland allerdings schwer zu bekommen. Eine alternative Therapie stellt die lokale Injektion von Glucantim (Meglumin-Antimonat) dar. Eine schnelle, kostengünstige und nebenwirkungsarme Möglichkeit bietet hingegen die Lokalbehandlung mittels Kryotherapie.

\section{Literatur}

1 Cunningham DD. On the presence of peculiar parasitic organisms in the tissue of a specimen of Delhi boil. Sci Mem Med Offic Army India 1885; 1: $21-31$

2 Davies CR, Kaye P, Croft SL et al. Leishmaniasis: new approaches to disease control. BMJ 2003; 326: 377-382

3 Alrajhi AA, Ibrahim EA, De Vol EB et al. Fluconazole for the treatment of cutaneous leishmaniasis caused by Leishmania major. N Engl J Med 2002; 346: 891 - 895

4 López L, Robayo M, Vargas $M$ et al. Thermotherapy. An alternative for the treatment of American cutaneous leishmaniasis. Trials 2012; 13: 58

Ausgeprägte Verrucae vulgaris beim Saldino-MainzerSyndrom

\section{$\nabla$}

\section{Meister}

Anamnese: Es stellte sich eine 10-jährige Patientin mit teilweise schmerzenden, warzigen Hautveränderungen an den Händen und Füßen vor, die laut des Vaters im Verlauf der letzten drei Monate entstanden seien. Die Patientin litt an dem seltenen Saldino-Mainzer-Syndrom und hatte aufgrund einer begleitenden, schweren Nephropathie vor zwei Jahren eine Nierentransplantation erhalten. Seither wurde die junge Patientin mit Tacrolimus und Mycophenolatmofetil konsequent systemisch immunsupprimiert.

Untersuchungsbefund: Es fanden sich vor allem an den Kleinzehen beidseits massive Hyperkeratosen, die das Nagelorgan überwucherten, begleitend von einer schweren Nageldystrophie ( $\bullet$ Abb. 16). Die Fußsohlen zeigten hyperkeratotische Plaques mit Punktblutungen. An den Endphalangen der Finger waren kleinere, bis zu einen Zentimeter große, gelbliche Hyperkeratosen mit Punktblutungen zu sehen.

Therapie und Verlauf: Aufgrund des Alters der Patientin verzichteten wir zunächst auf eine Probebiopsie zur diagnostischen Sicherung, sondern gingen rein klinisch von ausgeprägten Verrucae vulgaris aus. Wir initiierten eine Lokaltherapie mit DuofilmLösung (Salicylsäure und Milchsäure) und Verrumal (Fluorouracil und Salicylsäure). Hierunter kam es innerhalb von drei Monaten zu einem deutlichen Rückgang der Verrucae, sodass auf eine

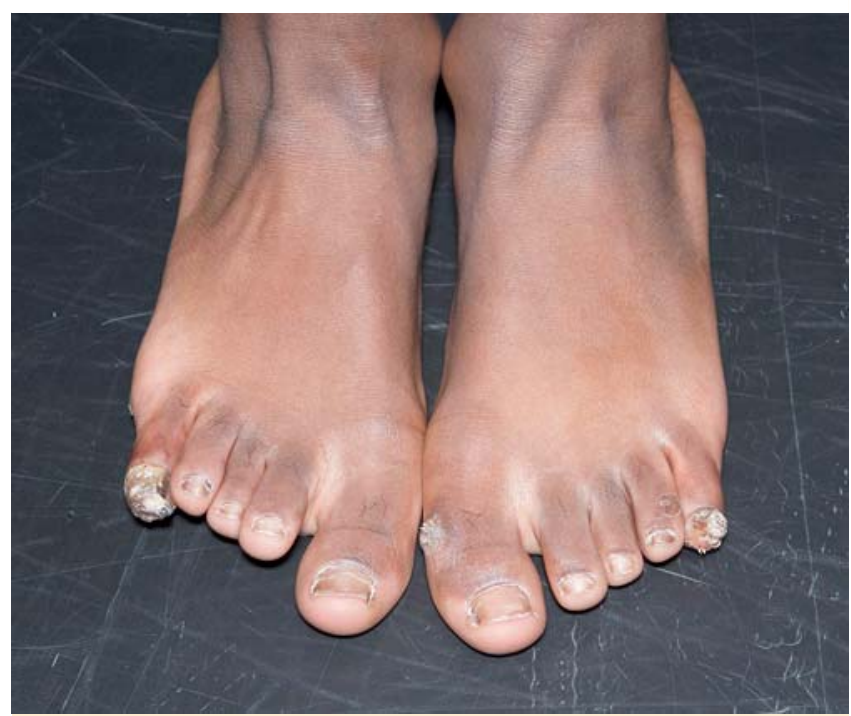

Abb.16 Füße: Massive, teils destruktive Hyperkeratosen beider Kleinzehen sowie medialseitig der linken Großzehe. 


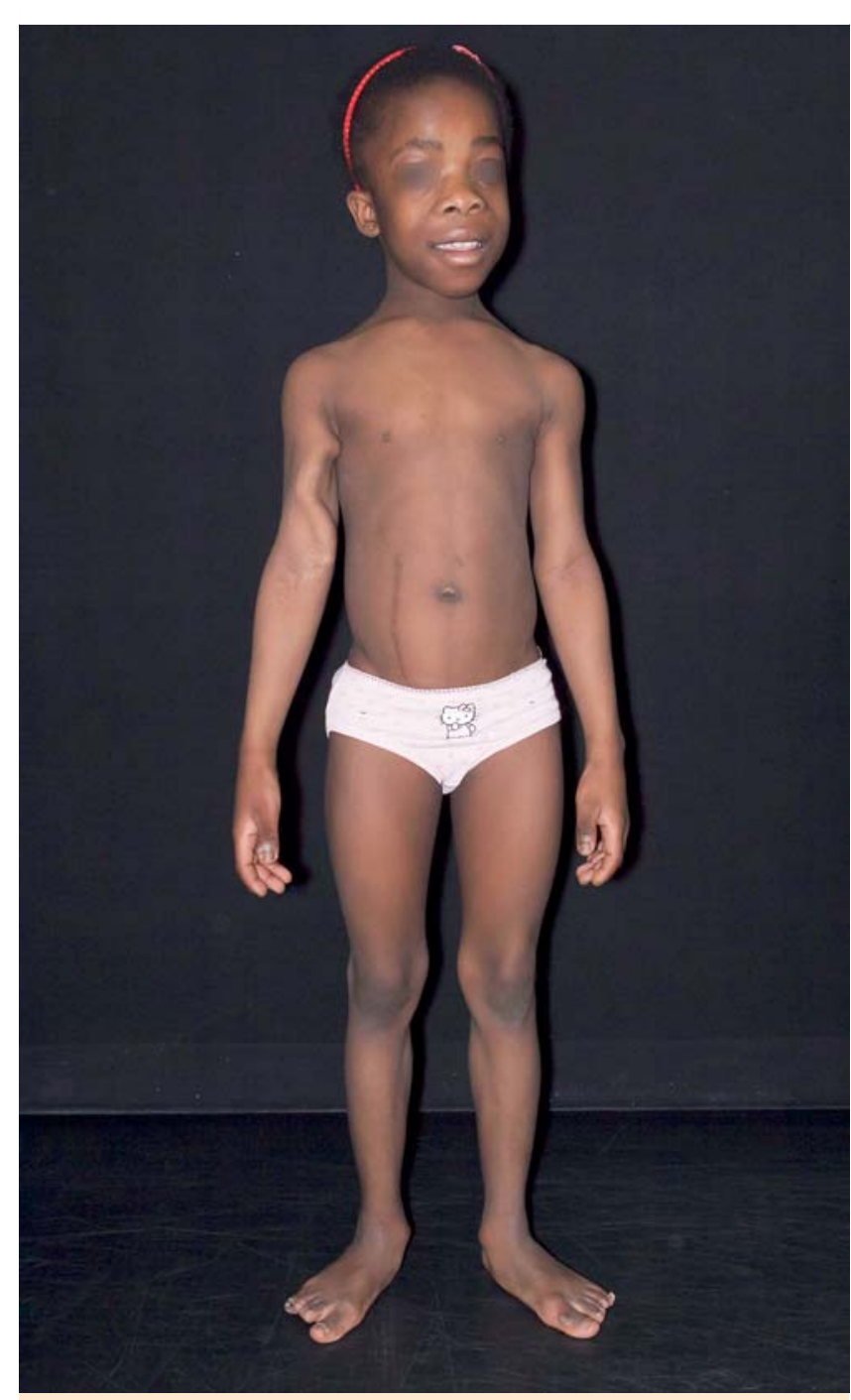

Abb.17 Übersicht: Phänotypische Veränderung beim Saldino-MainzerSyndrom mit moderatem Kleinwuchs und Veränderungen des Achsenskelettes.

bereits geplante chirurgische Intervention inklusive bioptischer Sicherung in Vollnarkose verzichtet werden konnte.

Kommentar: Das Saldino-Mainzer-Syndrom wird autosomal-rezessiv aufgrund einer Mutation im IFT140-Gen vererbt. Nur wenige Fälle wurden bisher in der Literatur beschrieben. Die Patienten weisen eine Nephropathie durch eine tubulointerstitielle Nephritis, Pigmentdystrophie der Retina und eine zerebelläre Ataxie auf. Daher entwickeln sie häufig bereits in der Kindheit eine Niereninsuffizienz sowie einen verminderten Visus bis hin zur Amaurosis. Ein weiteres Symptom ist leichter bis moderater Kleinwuchs und eine Skelettdysplasie ( $\bullet$ Abb. 17). Die typischen radiologischen Zeichen sind einerseits die verkürzten Phalangen und andererseits charakteristische Zapfenepiphysen. Typische Hautveränderungen sind bisher im Zusammenhang mit dem Saldino-Mainzer Syndrom nicht beschrieben worden. Die ausgeprägten Viruswarzen unserer Patientin sind am ehesten auf die immunsupprimierende Therapie nach der Nierentransplantation bei gleichzeitiger Inokulation von humanen Papillomaviren an der Haut zurückzuführen. Als Therapieoptionen der Verrucae vulgaris stehen verschiedene ablative Verfahren, die konsequente Keratolyse mit Reduktion der Warzenmasse sowie zytostatische und immunmodulatorische Lokaltherapien zur Verfügung.

\section{Literatur}

1 Mortellaro C, Bello L, Pucci A et al. Saldino-Mainzer syndrome: nephronophthisis, retinitis pigmentosa, and cone-shaped epiphyses. Craniofac Surg 2010; 21: $1554-1556$

2 Piaserico S, Sandini E, Peserico A et al. Cutaneous viral infections in organ transplant patients. Ital Dermatol Venereol 2014; 149: 409-415

3 Sułowicz J, Wojas-Pelc A, Ignacak E et al. Comparison of the prevalence frequency of infectious skin changes in dialyzed patients and after kidney transplantation. Przegl Lek 2013; 70: $41-47$

\section{Feldkanzerisierung und Psoriasis vulgaris - eine diagnostische und therapeutische Herausforderung $\nabla$ \\ J. Kleemann}

Anamnese: Die Vorstellung des 67-jährigen Patienten erfolgte bei ambulant therapierefraktärer, exazerbierter Psoriasis vulgaris. Der Patient leidet bereits seit seinem 16. Lebensjahr an einer Psoriasis vulgaris mit ebenfalls früh manifestierter Gelenkbeteiligung. Über einen Zeitraum von 15 Jahren erfolgte eine systemische Therapie mit Methotrexat(MTX) 20 mg s. c. $1 \times$ pro Woche. Intermittierend habe er zahlreiche UV-Bestrahlungen (UVB, PUVA) erhalten. Zwischenzeitlich wurde eine Therapie mit Acitretin begonnen, musste aber aufgrund von Nebenwirkungen abgebrochen werden. Parallel verwendete der Patient zusätzlich steroidhaltige und calcipotriolhaltige Externa bei Bedarf.

Untersuchungsbefund: Es finden sich streckseitig an den unteren und oberen Extremitäten sowie am Rumpf mit Betonung des Rückens große, teils flächig konfluierende, erythematöse Plaques mit typischer silbrig-weißer Schuppung ( $\bullet$ Abb. 18). Vereinzelt finden sich am gesamten Integument mit Betonung der Extremitäten im Bereich der beschriebenen erythematösen Plaques weitere abgrenzbare hyperkeratotische Knötchen.

Diagnostik: Bei klinischem Verdacht auf multiple aktinische Keratosen bzw. kutane Plattenepithelkarzinome im Bereich der Psoriasisplaques führten wir ein PE-Mapping durch. Hier zeigten sich neben der Psoriasis vulgaris auch das Bild einer Feldkanzerisierung mit Präkanzerosen sowie vereinzelt bereits gut bis mäßig differenzierte Plattenepithelkarzinome.

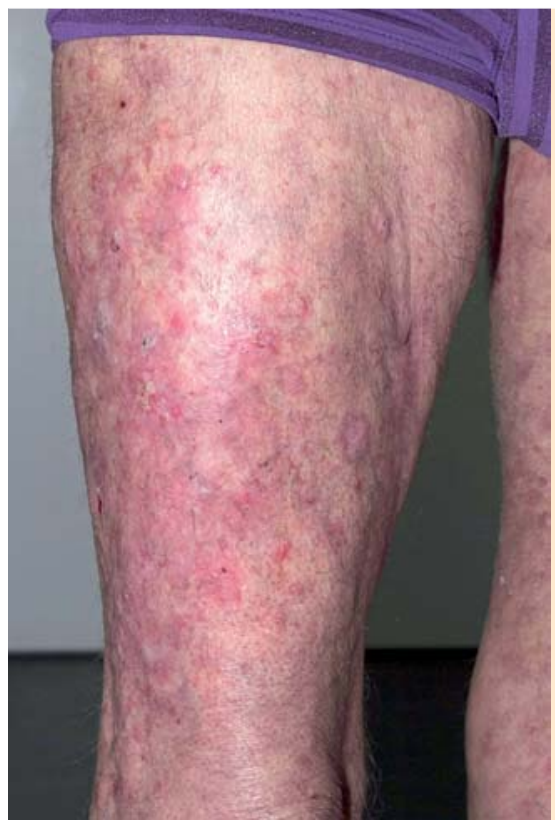

Abb. 18 Oberschenkel: Darstellung des rechten ventralen Oberschenkels mit typischen erythrosquamösen Veränderungen der Schuppenflechte und der Feldkanzerisierung durch aktinische Keratosen und kutane Plattenepithelkarzinome. Diese sind klinisch nicht voneinander zu unterscheiden. 


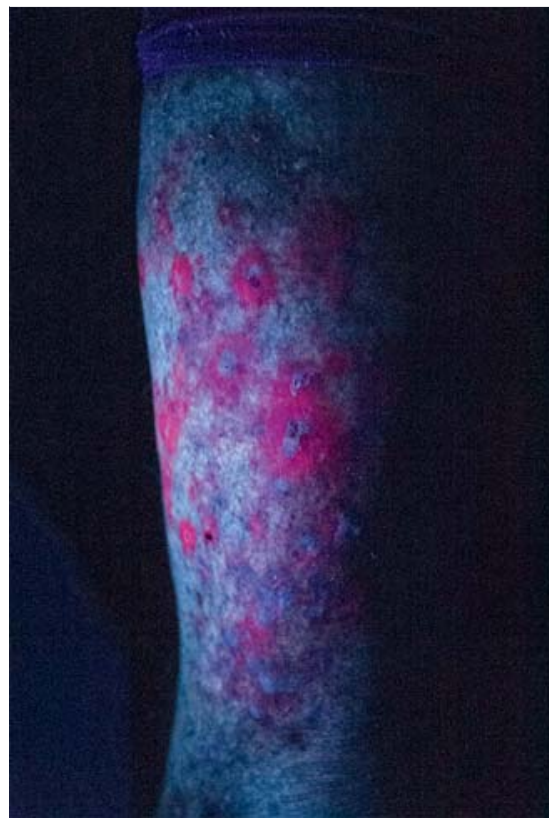

Abb. 19 Oberschenkel-PDD vorher:

Photodynamische Diagnostik (PDD) mit korallrot fluoreszierenden aktinischen Keratosen und Plattenepithelkarzinomen. Dagegen sind die psoriatischen Hautveränderungen nicht angefärbt und stellen sich bläulich dar.

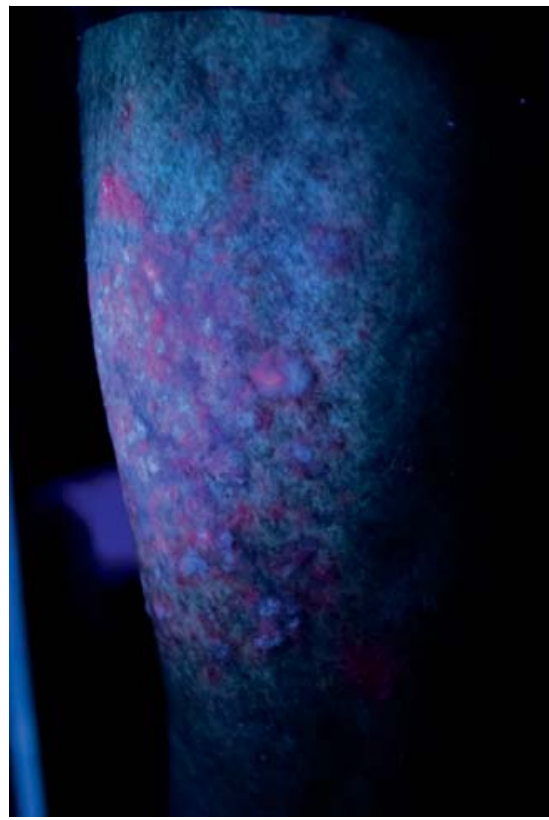

Abb. 20 Oberschenkel PDD nachher: Kontroll-PDD zwölf Wochen nach Durchführung der PDT mit deutlicher Abnahme der (prä)kanzerösen Areale.

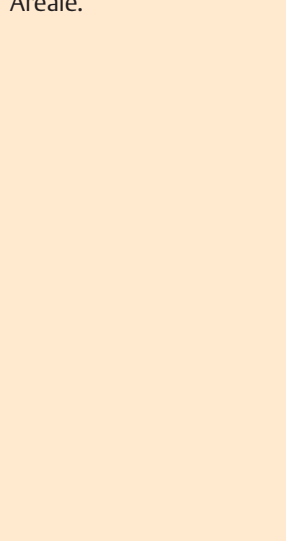

Bei der Schwierigkeit der klinischen Abgrenzung zwischen chronischen Lichtschäden und Psoriasis entschieden wir uns zur weiteren Differenzierung für eine photodynamische Diagnostik (PDD) mit Hilfe der Woodlichtlampe. Mittels PDD kann der weiße Hautkrebs gut durch das starke, korallrote Fluoreszenzmuster der angereicherten Protoporphyrine von den nicht fluoreszierenden Psoriasisherden unterschieden werden $\bullet$ (Abb. 19).

Histologie: Man sieht einen überwiegend parahyperkeratotisch verhornenden Tumor. Dieser besteht aus kompakten Formationen pleomorpher Keratinozyten. Es zeigen sich Mitosen, Einzelzellverhornungen und größere Hornperlen. In der Tiefe dringt der Tumor in asymmetrischer Anordnung bis ins Bindegewebe vor - passend zum kutanen Plattenepithelkarzinom.

Therapie und Verlauf: Histologisch gesicherte, invasive Tumore wurden mittels mikrografisch kontrollierter Exzision behandelt. Im Anschluss an die photodynamische Diagnostik erfolgte eine photodynamische Therapie (PDT) zur Flächenbehandlung der
Feldkanzerisierung am Oberschenkel. Zwölf Wochen nach einmaliger PDT erfolgte eine Kontroll-PDD. Hier zeigte sich ein deut-

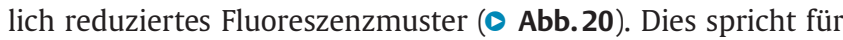
ein gutes Ansprechen der aktinischen Keratosen auf die Behandlung. Es trat nach der PDT keine Verschlechterung der ebenfalls bestrahlten Psoriasisherde auf. Bezüglich der exazerbierten Schuppenflechte erfolgte die Umstellung der Systemtherapie von MTX auf einen oralen Phosphodiesterase-4-Hemmer.

Kommentar: Klinisch ist die Unterscheidung zwischen Psoriasis vulgaris-typischen Hautveränderungen und einer Feldkanzerisierung durch aktinische Keratosen oder kutane Plattenepithelkarzinome nur sehr schwer möglich. Patienten, die aufgrund der Schuppenflechte über Jahrzehnte eine immunsuppressive Therapie und dazu zahlreiche UV-Therapien mit hohen kumulativen UV-Dosen erhalten haben, bedürfen einer besonderen Aufmerksamkeit im Hinblick auf die Entwicklung von Hauttumoren. Gerade die Rasanz der Entwicklung des hellen Hautkrebses nach chronischer UV-,Überdosierung“ kann sich klinisch schnell zu einem größeren Problem entwickeln.

Die hier dargestellte photodynamische Diagnostik und Therapie stellt eine schnelle, nicht-invasive Alternative zum chirurgischhistologischen Vorgehen dar.

Einige Fallberichte existieren zum Einsatz der PDT für die Therapie der Psoriasisplaques. Im Vergleich zu den herkömmlichen Bestrahlungsformen (PUVA, UVB, UVB311) lässt sich aber keine signifikante Reduktion verzeichnen. Jedoch unterstützen diese Daten den Einsatz der PDT zur Therapie chronischer Lichtschäden im Bereich von psoriatischen Arealen.

\section{Literatur}

1 Choi YM, Adelzadeh L, Wu JJ. Photodynamic therapy for psoriasis. J Dermatolog Treat 2015; 26: 202-207

2 Almutawa F, Thalib L, Hekman D. Efficacy of localized phototherapy and photodynamic therapy for psoriasis: a systematic review and metaanalysis. Photodermatol Photoimmunol Photomed 2015; 31: 5-14

3 Park HJ, Ranganathan P. TNF-alpha antagonism and cancer risk in rheumatoid arthritis: is continued vigilance warranted? Discov Med 2012; 13: 229-234

\section{Seltene Form einer juvenilen Rosazea mit Entwicklung eines Rhinophyms \\ $\nabla$}

\section{F. Pfeifer}

Anamnese: Der 24-jährige Patient berichtet über seit der Pubertät konstant bestehende Hautveränderungen an der Nase mit Pusteln, persistierendem Erythem und Hyperplasie der Talgdrüsen. Seit zirka einem Jahr sei es zudem zu knotigen Hautveränderungen im Sinne eines Rhinophyms gekommen. Der Patient leidet an multiplen, sekundär aufgetretenen Grunderkrankungen wie Niereninsuffizienz, chronisch obstruktiver Lungenerkrankung, arteriellem Hypertonus und bekannter Hypogammaglobulinämie mit IgG4-Subklassenmangel. Es erfolgt die regelmäßige Gabe von Immunglobulin-G (720 mg, alle 3 Tage) und Ramipril.

Befund: Es finden sich im Bereich der Nasenspitze, des distalen Nasenrückens sowie an den Nasenflügeln einzelne Pusteln, erythematöse Knötchen, teils zu flächigen Plaques konfluierend, bei unterliegend lividem Erythem ( $\bullet$ Abb.21).

Therapie und Verlauf: Wir initiierten eine systemische Therapie mit teilretardiertem Doxycyclin $40 \mathrm{mg}$ einmal täglich. Eine Lokaltherapie erfolgte weiterhin mit Metronidazol-Gel sowie er- 


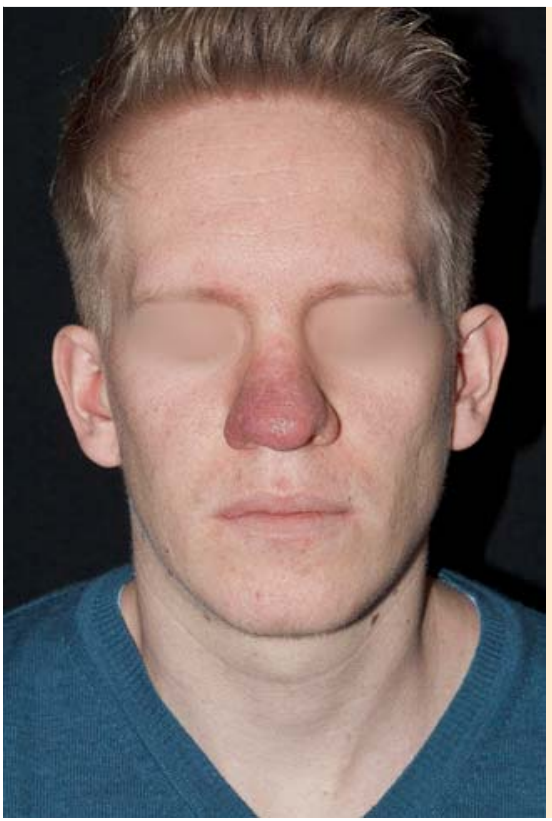

Abb.21 Rhinophym: Rhinophym bei einem 24-jährigen Patienten mit bekannter Hypogammaglobulinämie.

gänzend mit Brimonidin-Gel. In einer Verlaufskontrolle zeigte sich der Lokalbefund leicht gebessert und weniger entzündlich gerötet. Es wird eine Fortführung der Therapie über sechs Monate angestrebt.

Kommentar: Das Rinophym wird als benigner nasaler Hauttumor beschrieben. Es wird zum Formenkreis der Rosazea gezählt und gilt in der Form, wie es der Patient zeigt, als fortgeschrittenes Stadium (Stadium IV). Die Erkrankung tritt gehäuft beim hellhäutigen, männlichen Geschlecht im Verhältnis 12:1 auf und betrifft typischerweise Menschen frühestens ab dem 5. Lebensjahrzehnt. In der Literatur sind daher Berichte über Rhinophyme bei Patienten unter 30 Jahren eine Rarität. In den letzten 50 Jahren wurden lediglich fünf Fallberichte beschrieben.

Eine rosazeaähnliche Dermatitis mit Beginn in der Pubertät wird beim Haber-Syndrom beschrieben - ein wahrscheinlich autosomal-dominant vererbtes, persistierendes Gesichtserythem. Charakteristisch für das Harber-Syndrom sind persistierende, teilweise mit Schuppen bedeckte und mit Teleangiektasien durchsetzte Erytheme mit zahlreichen roten follikulären Hornpapeln. Diese finden sich diffus im Stirn-, Nasen- und Kinnbereich.

In der Fachliteratur finden sich bislang keine Berichte zur Assoziation eines Rhinophyms mit einer Hypogammaglobulinämie. Neuere Erkenntnisse zu Pathomechanismen der Rosazea zeigen jedoch Hinweise, dass eine Immundefizienz eine Rolle spielen kann. Besonders die natürliche Immunität scheint bei Rosazeapatienten geschwächt zu sein. So fanden sich in mehreren Patientenstämmen abnorm hohe Cathelicidinwerte (antimikrobielles Peptid). Diese beeinflussen die Chemotaxis von Leukozyten, die Angiogenese und die Expression von EZM-Komponenten. Bei der Seltenheit eines Rhinophyms unter 30 Jahren könnte über einen möglichen Zusammenhang der Hypogammaglobulinämie mit diesem multifaktoriellen Geschehen diskutiert werden.

\section{Literatur}

1 Popa D, Osman G, Parvanescu $H$ et al. The treatment of giant rhinophyma - case report. Curr Health Sci J 2012; 38: 41 - 44

2 Bittencourt $C$, Accionirover P, Filho AB et al. Rhinophyma in an adolescent. JEADV 2006; 18: $602-634$
Juckende Hyperkeratosen bei positiver atopischer Familienanamnese - Hyperkeratosis lenticularis perstans (Morbus Flegel)

$\nabla$

\section{Kalutzki}

Anamnese: Die Vorstellung der 72-jährigen Patientin erfolgte aufgrund von fünf Monate zuvor erstmals aufgetretenen und drei Monate später deutlich exazerbierten, stark juckenden Knötchen am gesamten Integument. Ein lokaler Behandlungsversuch mit Clotrimazol-Creme und Triamcinolon-Salbe zeigte keine Wirksamkeit. Die Patientin weist eine positive Familienanamnese bezüglich einer atopischen Dermatitis auf, ferner ist ein Mammakarzinom in der Vorgeschichte bekannt.

Befund: Am gesamten Integument mit Betonung der distalen Extremitäten zeigten sich disseminiert verteilte, multiple, bis zu $0,5 \mathrm{~cm}$ durchmessende, braunrote, hyperkeratotische Papeln mit vereinzelter zentraler Vertiefung ( $\bullet$ Abb.22).

Diagnostik: Histologisch fand sich eine deutlich atrophe Epidermis, stellenweise mit Orthohyperkeratose, teils mit Parahyperkeratose. Lockeres Entzündungsinfiltrat aus Lymphozyten im oberen Bindegewebe sowie eine deutliche aktinische Elastose ( $\bullet$ Abb. 23). Die erweiterte laborchemische und infektiologische Diagnostik sowie internistische Untersuchung blieben ohne wegweisenden Befund. In Übereinstimmung mit der klinischen

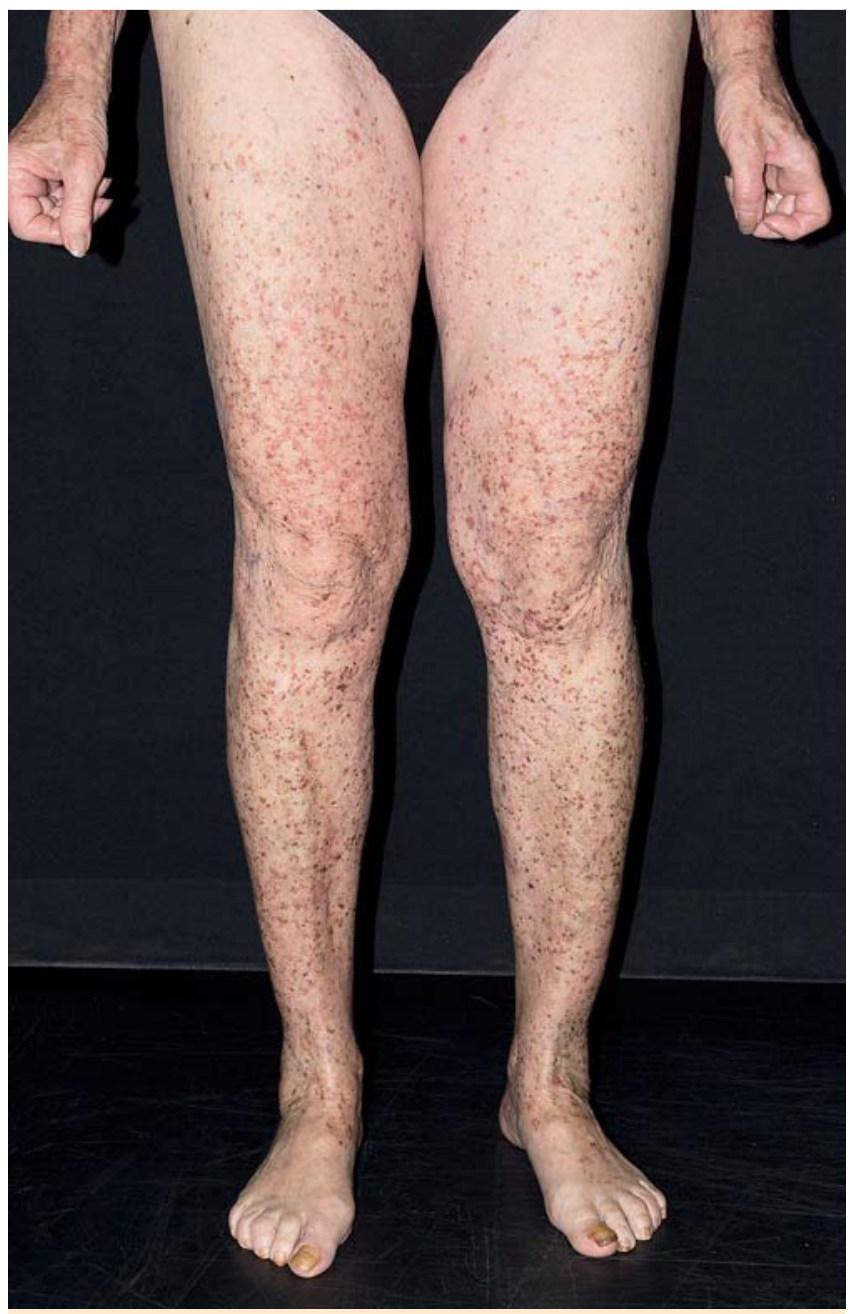

Abb.22 Morbus Flegel: Disseminiert verteilte, bräunliche Papeln, betont an den distalen unteren Extremitäten einer 72-jährigen Patientin. 


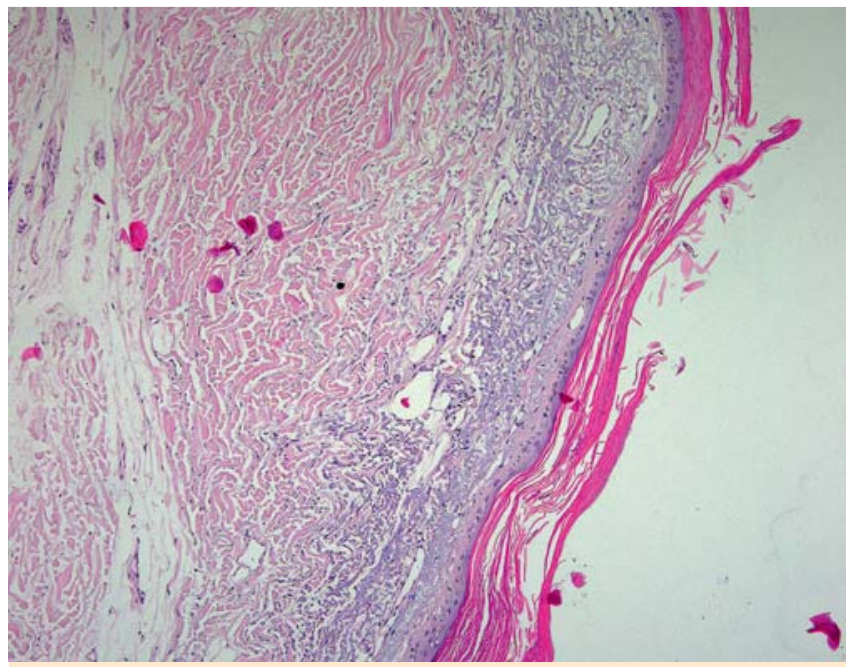

Abb.23 Histologie: Histologisch zeigt sich eine atrophe Epidermis mit Orthohyperkeratose sowie Parakeratose. Das subepidermale entzündliche Infiltrat besteht vornehmlich aus Lymphozyten (HE 100×).

Morphologie wurde durch die histologische Darstellung die Diagnose einer Hyperkeratosis lenticularis perstans (Morbus Flegel) gesichert.

Therapie und Verlauf: Die intensivierte Lokaltherapie mittels Salicylvaseline 5\% und Locacorten-Vioform-Creme zeigte initial kein Ansprechen. Daraufhin erfolgte ein Therapieversuch mit Acitretin $30 \mathrm{mg} / \mathrm{d}$ als Initialdosis und im Verlauf $25 \mathrm{mg} / \mathrm{d}$ als Erhaltungsdosis. Eine erste merkliche Regredienz des Befundes stellte sich erst im weiteren Verlauf zirka zwei Monate nach Einleitung der Systemtherapie ein und eine subtotale Erscheinungsfreiheit konnte erst sukzessive über einen Zeitraum von einem halben Jahr erreicht werden. Lokal führte die Patientin lediglich eine begleitende Therapie mit Pflegepräparaten durch.

Kommentar: Die Hyperkeratosis lenticularis perstans wurde 1958 erstmals vom deutschen Dermatologen Heinz Flegel beschrieben. Sie manifestiert sich hereditär (autosomal dominant), selten auch sporadisch, vorwiegend in der vierten und fünften Lebensdekade mit bevorzugter Lokalisation an den Unterschenkeln. Differenzialdiagnostisch kommen neben einer Psoriasis vulgaris oder einer Manifestation der atopischen Dermatitis auch seltene Dermatosen wie die Hyperkeratosis follicularis et parafollicularis in cutem penetrans (Morbus Kyrle), die Stukkokeratosis, Dyskeratosis follicularis oder Porokeratosis Mibelli in Betracht.

Das charakteristische Bild in der Elektronenmikroskopie sind die fehlenden Odland-Bodies in den Keratinozyten frischer Läsionen. Begünstigende Faktoren konnten nicht eindeutig ausgemacht werden, Berichte über Assoziationen zu verschiedenen Krankheitsbildern wie Endokrinopathie, Diabetes mellitus, Hypertonus oder Malignomen sind uneinheitlich. Die Therapieansätze beinhalten glukokortikoidhaltige, keratolytische und rehydratisierende Externa, topisches 5-FU und systemische Retinoide. Allerdings erweist sich diese zumeist asymptomatische Dermatose häufig als therapierefraktär bei ansonsten hervorragender Prognose.

\section{Literatur}

1 Flegel $H$. Hyperkeratosis lenticularis perstans. Hautarzt 1958; 9: 362 364

2 Krishnan A, Kar S. Photoletter to the editor: Hyperkeratosis lenticularis perstans (Flegel's disease) with unusual clinical presentation. Response to isotretinoin therapy. J Dermatol Case Rep 2012; 6: 93 -95
3 Price ML, Wilson Jones E, MacDonald DM. A clinicopathological study of Flegel's disease (hyperkeratosis lenticularis perstans). Br J Dermatol 1987; 116: $681-691$

\section{Elastolytisches Riesenzellgranulom mit atypischer Verteilung}

K. Hempel

Anamnese: Die Vorstellung der 42-jährigen Patientin erfolgte aufgrund von seit über zwei Jahren bestehenden, therapierefraktären, kleinherdigen, granulomatösen Papeln. Ex domo seien diese histologisch als Granuloma anulare gesichert worden. Insgesamt sei ein schwankender Verlauf und unter Neotigason $40 \mathrm{mg}$ nur initial eine Besserung zu verzeichnen gewesen. Einen Zusammenhang zur UV-Exposition habe die Patientin nicht bemerkt.

Untersuchungsbefund: An Decolleté, oberem Rücken bis zum Hals, vereinzelt auch an Oberschenkelvorderseiten und Handrücken finden sich multiple, 2 bis $10 \mathrm{~mm}$ große, anuläre Papeln mit erhabenem, festen Rand sowie zentraler Atrophie und Abblassung. Zum Teil finden sich durch Konfluenz der Befunde auch zirzinäre Formationen $(\bullet$ Abb.24).

Histologie: Es zeigt sich eine kompakte, orthokeratotische Verhornung sowie perivaskulär eine überwiegend lymphozytäre Immunreaktion. Es kommen mehrkernige Riesenzellen zur Darstellung sowie einzelne kleinere Pallisadengranulome. Oberflächlich dermal und im Bereich der Entzündungsreaktion lässt sich vermehrt Muzin nachweisen. In dem betroffenen Areal zeigt sich ein Abbau der elastotischen Fasern. Kein Nachweis intrakornealer Pilzhyphen ( $\bullet$ Abb. 25).

Therapie und Verlauf: Es wurde eine Therapie mit Resochin $250 \mathrm{mg}$ tgl. p.o. eingeleitet, Neotigason hingegen abgesetzt. Blutbild, Elektrolyte, Nierenwerte und Transaminasen waren normwertig. Nebenbefundlich zeigten die Schilddrüsenwerte

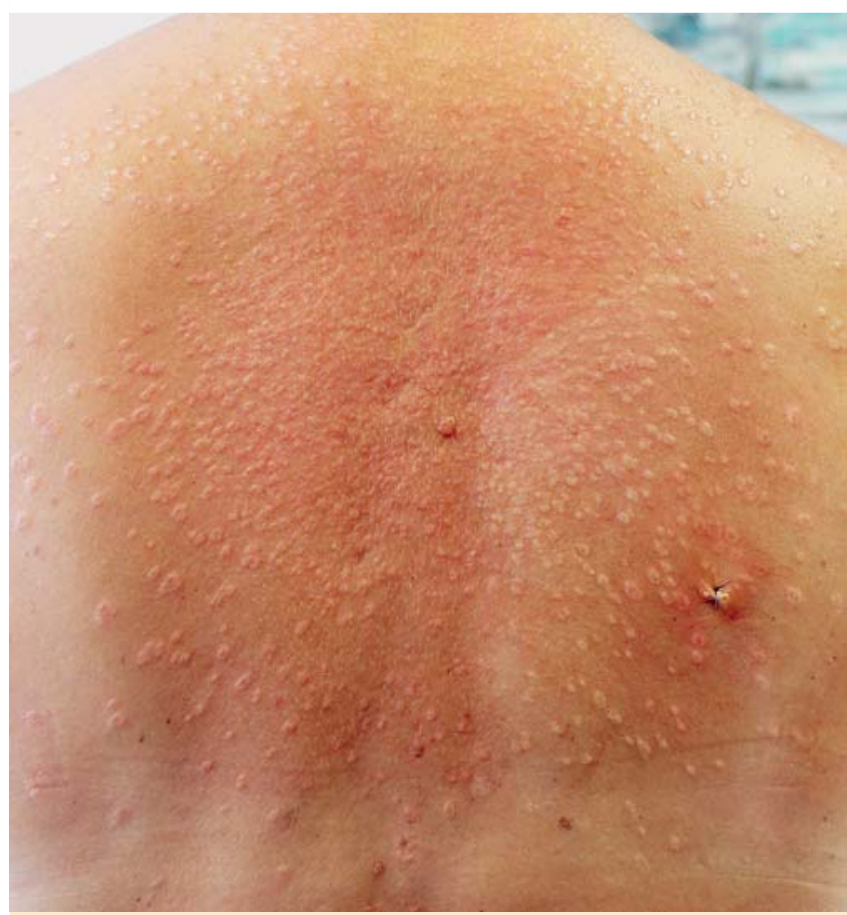

Abb.24 Multiple, hautfarbene, konfluierende, symptomlose anuläre Papeln am oberen Rücken der 42-jährigen Patientin. 


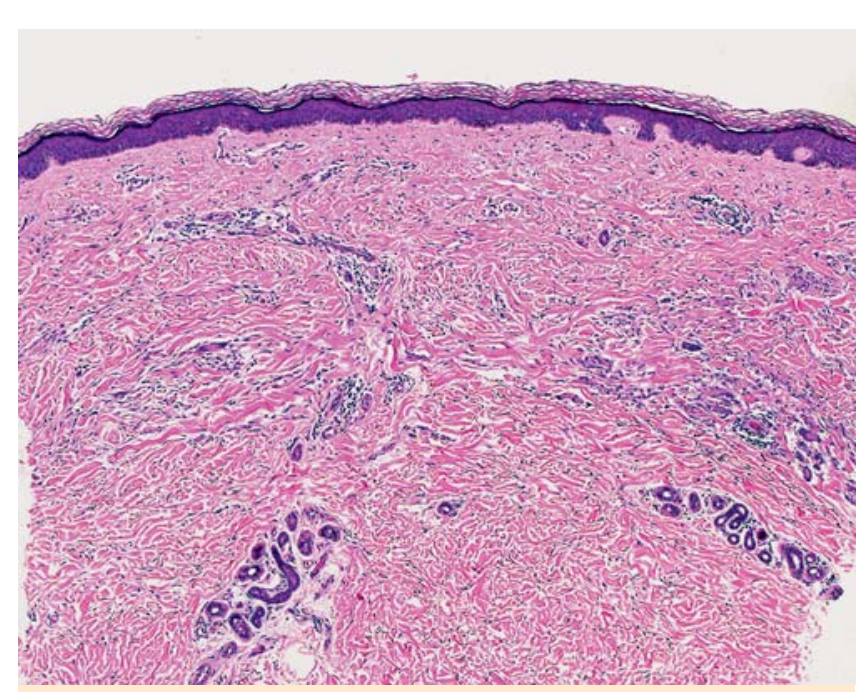

Abb. 25 Histologie: Kompakte Orthokeratose der Epidermis mit dermalem, perivaskulär liegendem, lymphozytärem Entzündungsinfiltrat. Charakteristisch sind die mehrkernigen Riesenzellen und die Pallisadengranulome (HE 40×).

eine TPO-AK-Erhöhung mit resultierender sonografisch bestätigter Diagnose einer Autoimmunthyreoiditis ohne Anhalt auf Malignität. Ein Zusammenhang zum beschriebenen Hautbefund erscheint unwahrscheinlich. Unter der oben genannten Therapie zeigte sich eine Besserung des Befundes.

Kommentar: Das anuläre elastolytische Riesenzellgranulom ist eine seltene granulomatöse Hautkrankheit, die durch den Verlust von elastischen Fasern zusammen mit Elastophagozytose durch mehrkernige Riesenzellen gekennzeichnet ist.

Klinisch präsentieren sich kleine Papeln, die sich zu anulären und serpiginösen Plaques mit leicht erhabenem Rand entwickeln. Das Zentrum der Läsion kann Hypopigmentierung, atrophische Veränderungen oder beides präsentieren. Diese treten am häufigsten an lichtexponierten Arealen auf, finden sich aber, wenn auch seltener, an lichtgeschützten Hautpartien. Die Ätiopathogenese dieser Erkrankung ist unklar. Es wird angenommen, dass UVStrahlung, Wärme oder weitere unbekannte Faktoren die Antigenität der elastischen Fasern transformieren und dadurch eine zelluläre Immunantwort induzieren. Gewöhnlich zeigt sich ein chronischer Verlauf, obwohl Fälle von Spontanremission beschrieben wurden.

Es existiert keine Standardtherapie für die Erkrankung und es sind eine Vielzahl an Therapien beschrieben, u.a. mit intraläsionalen oder systemischen Kortikosteroiden, Exzision solitärer Herde, Retinoid-PUVA, Cyclosporin, topischer Applikation von Tacrolimus oder Pimecrolimus, topischen Steroiden, Dapson, Fumarsäureestern und Schmalband-UVB.

Darüber hinaus existieren Fallberichte über Clofazimin als wirksame und unwirksame Therapie. Die Therapieerfolge mit Resochin für das anuläre elastolytische Riesenzellgranulom stellen sich in der Literatur variabel dar. Es konnten Therapieerfolge bei Patienten mit generalisiertem anulärem elastolytischem Riesenzellgranulom mit Resochin verzeichnet werden, welche nicht auf die Therapie mit Clofazamin ansprachen. Auch wenn die Möglichkeit einer Spontanremission nicht ausgeschlossen werden konnte, so wurde der Progress der Erkrankung gestoppt und Läsionen zur Abheilung gebracht. Daher scheint Hydroxychloroquin eine wirksame und sichere Alternative zur Behandlung des anulären elastolytischen Riesenzellgranuloms zu sein.

\section{Literatur}

1 Can B, Kavala M, Türkoðlu Z et al. Successful treatment of annular elastolytic giant cell granuloma with hydroxychloroquine. Int J Dermatol 2013; 52: 509-511

2 Lee HW, Lee MW, Choi JH et al. Annular elastolytic giant cell granuloma in an infant: Improvement after treatment with oral tranilast and topical pimecrolimus. J Am Acad Dermatol 2005; 535 (Suppl. 1): 244 246

3 Ozkaya-Bayazit E, Buyukbabani N, Baykal C et al. Annular elastolytic giant cell granuloma: sparing of a burn scar and successful treatment with chloroquine. Br J Dermatol 1999; 140: 525-530

4 Vehring KH, Bonsmann G, Brocker EB et al. Annular elastolytic giant cell granuloma - differential diagnosis of cutaneous granulomatosis. Hautarzt 1991; 42: $391-395$

\section{Schmerzhafte Ekchymosen - Gardner-Diamond- Syndrom als seltene Differenzialdiagnose}

$\nabla$

\section{Schopper}

Anamnese: Eine 20-jährige Patientin stellte sich anamnestisch mit seit zirka vier Wochen bestehenden, stark schmerzhaften Einblutungen an beiden Mammae vor. Die ausgeprägten Schmerzen wurden regelmäßig mit Tilidin behandelt. Weiterhin war die Patientin aufgrund der Beschwerden bereits über längere Zeit arbeitsunfähig. Bei der Erstvorstellung wirkte die Patientin auffällig unbekümmert und nicht sehr beeinträchtigt durch das Krankheitsbild. Gemeinsam mit der Arbeitsunfähigkeit und den starken Schmerzen ergab dies ein inadäquates Krankheitsbild.

Befund: Ausschließlich an beiden Mammae zeigten sich flächige, braun-gelbe, bis zu $4 \times 6 \mathrm{~cm}$ unscharf begrenzte Maculae im Sinne von älteren Ekchymosen und zum Teil linear angeordnete, frische, oberflächliche Petechien ( $\bullet$ Abb.26).

Diagnostik: Die Gerinnungsdiagnostik umfasste das Differenzialblutbild, Fibrinogen, Antithrombin III, Protein C, INR, PTT und PTZ, zeigte sich aber komplett unauffällig. Die schmerzhaften Einblutungen ließen uns an ein Gardner-Diamond-Syndrom denken - eine Autoimmunreaktion gegen körpereigene Erythrozyten. Daher wurde ein autologer Erythrozytentest mit $\mathrm{NaCl}$ 0,9\% als Negativkontrolle an einer von der Patientin nicht erreichbaren Stelle am Rücken und an den Unterarmen durchgeführt. Zum Ablesezeitpunkt nach drei und sechs Stunden konnte keine Reaktion festgestellt werden. Interessanterweise kehrte die

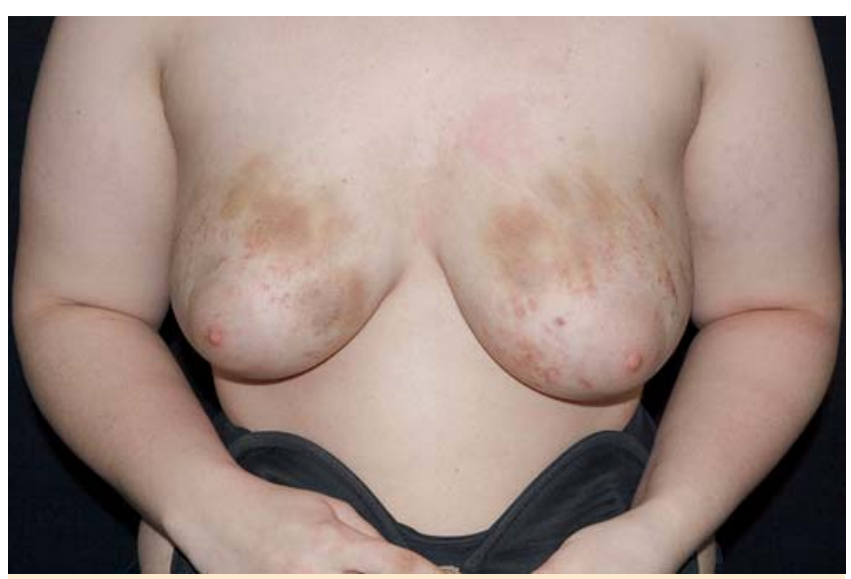

Abb.26 Brust: Multiple frische und ältere Ekchymosen, symmetrisch an beiden Mammae, lassen an einen länger andauernden Krankheitsverlauf denken. 


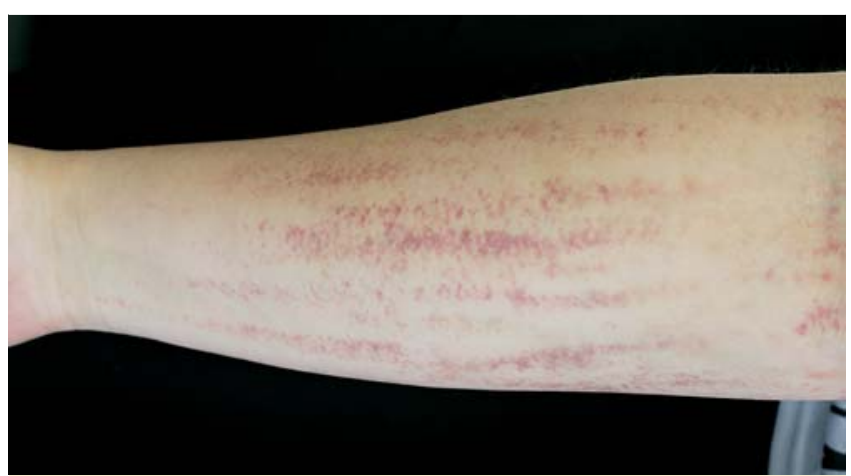

Abb.27 Arm: Longitudinal und parallel angeordnete Hämatome am rechten Unterarm.

Patientin etwa eine Woche nach der Durchführung des Testes erneut in unsere Ambulanz zurück und präsentierte wiederum longitudinal angeordnete Einblutungen an beiden Armen ( $\bullet$ Abb.27). Diese waren nicht mehr eine Folge des autologen Erythrozytentests sondern mussten manipulativ-artifiziell von der Patientin hervorgebracht worden sein.

Kommentar: Das Gardner-Diamond-Syndrom ist gekennzeichnet durch spontanes Auftreten von schmerzhaften Hauteinblutungen. Es tritt vor allem bei jungen Frauen auf. Die Ätiopathogenese ist noch nicht geklärt. Neben psychogenen Einflüssen scheinen Autoantikörper gegen Bestandteile der Erythrozytenmembran (Phosphatidylserin) eine Rolle zu spielen. Der Nachweis mittels autologer Erythrozyteninjektion ist nur in 60-80\% der Fälle positiv. Bei unserer Patientin zeigte sich bei einer erneuten Vorstellung an beiden Unterarmen in langen Streifen angeordnete Einblutung, sodass wir letztendlich die Hautveränderungen als Artefakte einstuften und somit ein Gardner-Diamond Syndrom ausschließen konnten. Es erfolgte eine Anbindung der Patientin an die Psychiatrie, wo eine artifiziell-autoaggressive Störung bestätigt und eine medikamentöse Therapie sowie eine Verhaltenstherapie begonnen wurde. Eine Behandlung der Hautveränderungen war somit nicht mehr notwendig.

\section{Literatur}

1 Groch GS, Finch SC, Rogoway $W$ et al. Studies in the pathogenesis of autoerythrocyte sensitization syndrome. Blood 1966; 28: 19-33

2 Jafferany M, Bhattacharya G. Psychogenic Purpura (Gardner-Diamond Syndrome). Prim Care Companion CNS Disord 2015; 22: 17

\section{Acrokeratosis paraneoplastica Bazex - immer eine Paraneoplasie? \\ $\nabla$}

\section{A. Valipour}

Anamnese: Die Vorstellung des 55-jährigen Patienten erfolgte aufgrund von seit drei Monaten bestehenden Hautveränderungen an beiden Palmae und Plantae. Seit etwa einem Monat habe sich zudem eine gelblich verfärbte, massive Verdickung der Finger und Fußnägel entwickelt. Ambulant wurde eine Behandlung mit Clobegalen verordnet, welche keinen anhaltenden Effekt zeigte. Zusätzlich habe der Patient eine ausgeprägte B-Symptomatik mit Nachtschweiß und $8 \mathrm{~kg}$ Gewichtsverlust über zwei Monate entwickelt. Anamnestisch war der Patient zuvor immer hautgesund.

Untersuchungsbefund: An beiden Palmae und Plantae zeigen sich hyperkeratotische Plaques, leicht schuppend, teilweise verhornt auf leicht erythematösem Grund ( $\bullet$ Abb.28a und b). Zudem sieht man bis zu etwa $1 \mathrm{~cm}$ große, subunguale Hyperkeratosen. Ferner lassen sich gelblich-bräunliche Dyschromasien sowie z.T. Dystrophien der Nägel feststellen.

Histologie: Histologisch erscheint die Epidermis psoriaform akanthotisch und weist eine parahyperkeratotische Verhornung sowie eine Papillomatose auf. Unterhalb der Epidermis sieht man ein gefäßorientiertes Entzündungsinfiltrat aus Lymphozyten und Makrophagen. In der Alcian-PAS-Färbung ergibt sich kein Nachweis von intrakornealen Pilzhyphen ( $\bullet$ Abb. 29).

Therapie und Verlauf: In Korrelation mit der Histologie ordneten wir die Hautveränderungen als Acrokeratosis paraneoplastica Bazex ein. Eine umfangreiche Tumordiagnostik inklusive Bronchoskopie, Panendoskopie, ÖGD, Koloskopie sowie CT-Abdomen ergab aber zum aktuellen Zeitpunkt keinen Anhalt für eine maligne Neoplasie. Lediglich im CT-Thorax zeigten sich pulmonal multiple, weit unter $1 \mathrm{~cm}$ große Rundherde, die einer CT-gesteuerten Punktion nicht zugänglich waren. Radiologisch wurden daher regelmäßige Kontrollen zur Bewertung der Dynamik der Befunde empfohlen.

Wir entschlossen uns zunächst für eine rein symptomatische Therapie. Lokaltherapeutisch kamen 5\% Salicylsäure in DAC-Basiscreme zum Einsatz. Nach Keratolyse erfolgte die Behandlung mit Prednicarbat-Creme. Unter diesen Maßnahmen konnte ein Rückgang der hyperkeratotischen Plaques erzielt werden.

Kommentar: Die Acrokeratosis paraneoplastica Bazex ist eine seltene, meist paraneoplastische Dermatose. Sie befällt vor allem Männer ab der vierten Lebensdekade und kann einem Malignom

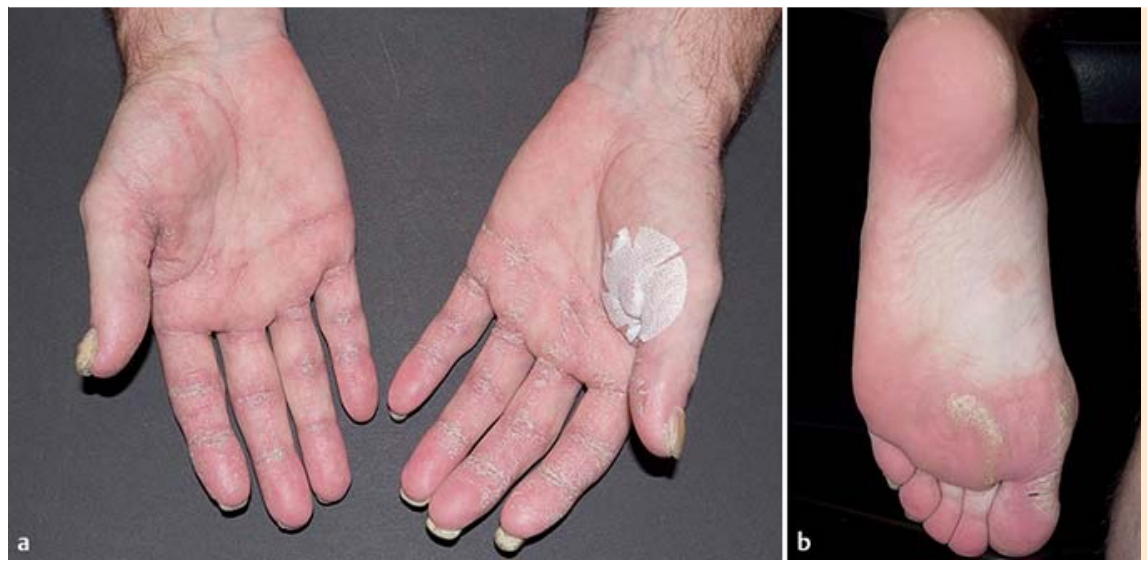

Abb.28 Acrokeratosis Bazex. a Mildes palmares Erythem mit distal betonter Schuppung. b Flächenhaftes plantares Erythem mit Aussparung des Längsgewölbes sowie umschriebenen Hyperkeratosen am medialen und medianen Fußballen. 


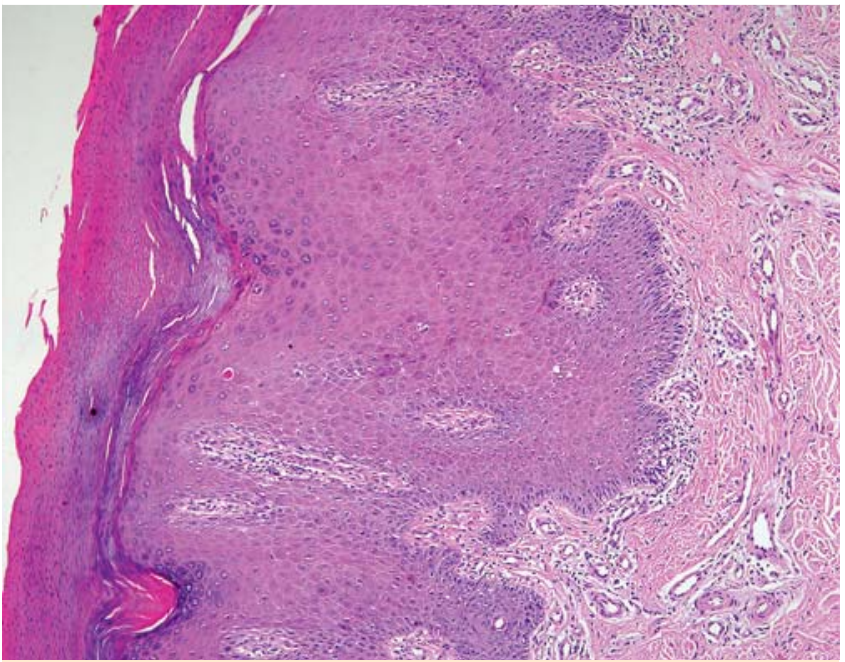

Abb. 29 Histologie: Parahyperkeratotische Verhornung der oberen Epidermis mit deutlicher Papillomatose. Das subepidermale, perivaskuläre Entzündungsinfiltrat besteht vornehmlich aus Lymphozyten und Makrophagen (HE 200×).

bis zu einem Jahr vorhergehen. Charakteristisch für dieses Krankheitsbild ist der erythrosquamöse Befall der Akren - also Hände, Füße, Ohren oder sogar der Nase - mit z.T. ausgeprägten Hyperkeratosen. Differenzialdiagnostisch kommen Erkrankungen wie eine Psoriasis palmoplantaris in Betracht.

Da Plattenepithelkarzinome des oberen aerodigestiven Systems am häufigsten die Ursache dieses Krankheitsbildes darstellen, sollte eine gezielte Fokussuche in diesem Bereich erfolgen. Andere Tumorentitäten wie das Plattenepithelkarzinom des Thymus oder der Vulva, das Adenokarzinom des Uterus oder das anaplastische, kleinzellige Karzinom der Lunge sind ebenfalls beschrieben. Generell führt die Behandlung der zugrundeliegenden Krankheit zu einem Rückgang der Hautveränderungen, sodass eine Tumorsuche und -sanierung anzustreben sind. Sollte hingegen keine maligne Erkrankung diagnostiziert worden sein, empfiehlt sich trotzdem eine regelmäßige Tumorsuche, da Befunde erst mit teilweiser großer Latenz entdeckt werden können.

\section{Literatur}

1 Silva JA, Mesquita Kde C, Igreja AC et al. Paraneoplastic cutaneous manifestations: concepts and updates. An Bras Dermatol 2013; 88: 09-22

2 Ehst BD, Minzer-Conzetti K, Swerdlin A et al. Cutaneous manifestations of internal malignancy. Current problems in surgery 2010; 47: 384445

\section{Erythema gyratum repens bei Myelodysplastischem Syndrom (Gammel-disease) \\ $\nabla$}

\section{A. Valipour}

Anamnese: Die Vorstellung der 71-jährigen Patientin erfolgte aufgrund einer seit 14 Tagen bestehenden geröteten Hautveränderung am Unterschenkel rechts lateral. Zunächst sei die Patientin von einem Insektenstich ausgegangen. Der Befund sei im Verlauf rasch progredient gewesen und zeigte zentral eine Blase auf, weshalb die Patientin ihre Hausärztin konsultierte. Im Verlauf sei weiterhin auffällig gewesen, dass der Hb-Wert binnen vier Wochen um vier Punkte gefallen sei.

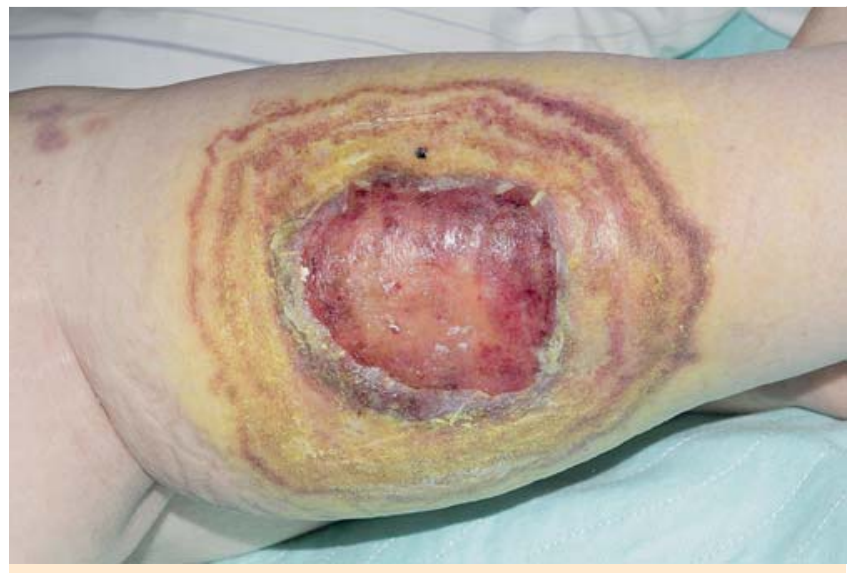

Abb.30 EGR: Lateraler rechter Unterschenkel mit zentraler Ulzeration und für das Krankheitsbild charakteristischen anulären, girlandenförmigen, livid-roten Maculae.

Untersuchungsbefund: Es zeigt sich am Unterschenkel rechts lateral eine ca. $10 \mathrm{~cm}$ messende Ulzeration, die von drei anulären, livid-roten, girlandenförmigen und ca. $1 \mathrm{~cm}$ breiten Maculae umgeben war $(\bullet$ Abb.30).

Histologie: In der Histologie zeigt sich eine orthokeratotische Verhornung. Das Epithel weist eine geringe Akanthose und eine ausgeprägte Anzahl an balonierten Keratinozyten auf. Subepidermal zeigt sich eine deutliche Leukozytoklasie in den entzündlichen Infiltraten. Zusammenfassend zeigt sich eine vaskulär dominierte Immunreaktion mit frischen Hämorrhagien und reichlich neutrophilen Granulozyten $(\bullet$ Abb.31).

Therapie und Verlauf: Bei Verdacht auf ein Erythema gyratum repens im Rahmen eines paraneoplastischen Syndroms erfolgte zunächst eine erweiterte Tumordiagnostik. Diese beinhaltete ein gynäkologisches Konsil, eine Koloskopie, ein Röntgen-Thorax und eine Sonografie des Abdomens und der Lymphknoten. Sämtliche Untersuchungen fielen negativ aus. Zudem wurde aufgrund des Hb-Abfalls ein hämatologisches Konsil gestellt. Nach Eingang des Differenzialblutbildes mit peripheren Blasten und einer an-

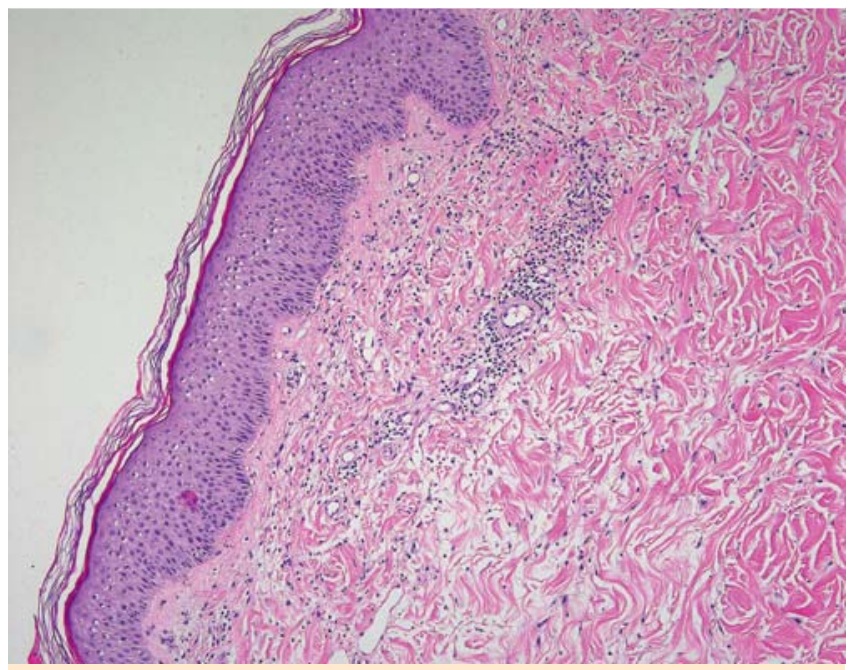

Abb. 31 Histologie: Orthokeratose mit geringfügiger Akanthose sowie balonierten Keratinozyten im oberen Anteil der Epidermis. Subepidermal liegendes Entzündungsinfiltrat aus neutrophilen Granulozyten mit Zeichen der Leukoklasie (HE 100×). 
schließenden Knochenmarkspunktion konnte die Diagnose eines myelodysplastischen Syndroms gestellt werden.

In Zusammenschau des hämatologischen Befundes mit der neu entstandenen Hautveränderung wurde das Hautbild als ein Erythema gyratum repens im Rahmen eines paraneoplastischen Phänomens eingestuft. Lokal kamen zunächst Locacorten-Vioform-Paste sowie ein Hydrogel-Polyurethanschaumverband zum Einsatz. Im Verlauf wechselten wir auf eine 0,1\%ige Triamcinolonacetonid-Creme. Darunter zeigte sich zwar eine Besserung des Hautbefundes - jedoch verstarb die Patientin bereits vier Wochen nach der Diagnosestellung.

Kommentar: Das Erythema gyratum repens (EGR) wurde erstmalig 1952 von Johann Gammel bei einer Patientin mit Mammakarzinom beschrieben. Charakteristisch für diese seltene Dermatose sind am Stamm und den Extremitäten vorkommende, anuläre, girlandenförmige, leicht infiltrierte und schnell wachsende Erytheme und Plaques, die als holzmaserungsartig beschrieben werden. Akren und Gesicht zeigen sich meist nicht betroffen.

Zunächst wurde das EGR als eine obligate kutane Paraneoplasie angesehen. Rongioletti et al. konnten 2014 in einer systematischen Übersichtsarbeit zeigen, dass lediglich 70\% der Patienten an einer malignen Paraneoplasie litten. Vergesellschaftet ist die Hauterscheinung mit Tumoren wie z.B. dem Lungen-, Ösophagus- oder Mammakarzinom. 30\% der Fälle traten idiopathisch oder begleitend zu einer Pityriasis rubra pilaris, Psoriasis vulgaris oder Ichthyosis auf. Bei den nicht-neoplastischen Fällen führte die Behandlung der jeweiligen Grunderkrankung bzw. eine Therapie mit topischen Glukokortikoiden, wie z.B. Triamcinolon $0,1 \%$, zu einer Verbesserung des Hautbildes. Als zwar seltenes dermatologisches Krankheitsbild sollte man diese Diagnose (er-)kennen um eine entsprechende Tumordiagnostik in die Wege zu leiten.

\section{Literatur}

1 Gammel JA. Erythema gyratum repens; skin manifestations in patient with carcinoma of breast. AMA Arch Derm Syphilol 1952; 66: 494505

2 Rongioletti F, Fausti V, Parodi A. Erythema gyratum repens is not an obligate paraneoplastic disease: a systematic review of the literature and personal experience. Journal of the European Academy of Dermatology and Venereology 2014; 28: 112-115

\section{Fallbericht eines metastasierten Schleimhaut- melanoms mit partiellem Ansprechen auf Ipilimumab und kompletter Remission unter Pembrolizumab-Therapie \\ $\nabla$ \\ K. Weid}

Anamnese: Die Vorstellung der 69-jährigen Patientin in unserer Ambulanz erfolgte aufgrund der Erstdiagnose eines kleinzelligen, stark proliferierenden Schleimhautmelanoms vom nodulär-amelanotischen Typ im Januar 2013. Der Primarius des Melanoms befand sich am Anoderm und an der Rektumschleimhaut (TD $15 \mathrm{~mm}$ ). Der Primarius wurde initial nicht komplett im Gesunden resiziert - eine umfassendere Nachexzision erforderte aber die Anlage eines Enterostomas und wurde daher von der Patientin abgelehnt. Die radiologischen Kontrollaufnahmen ergaben zu diesem Zeitpunkt keinen Hinweis auf eine Filialisierung.
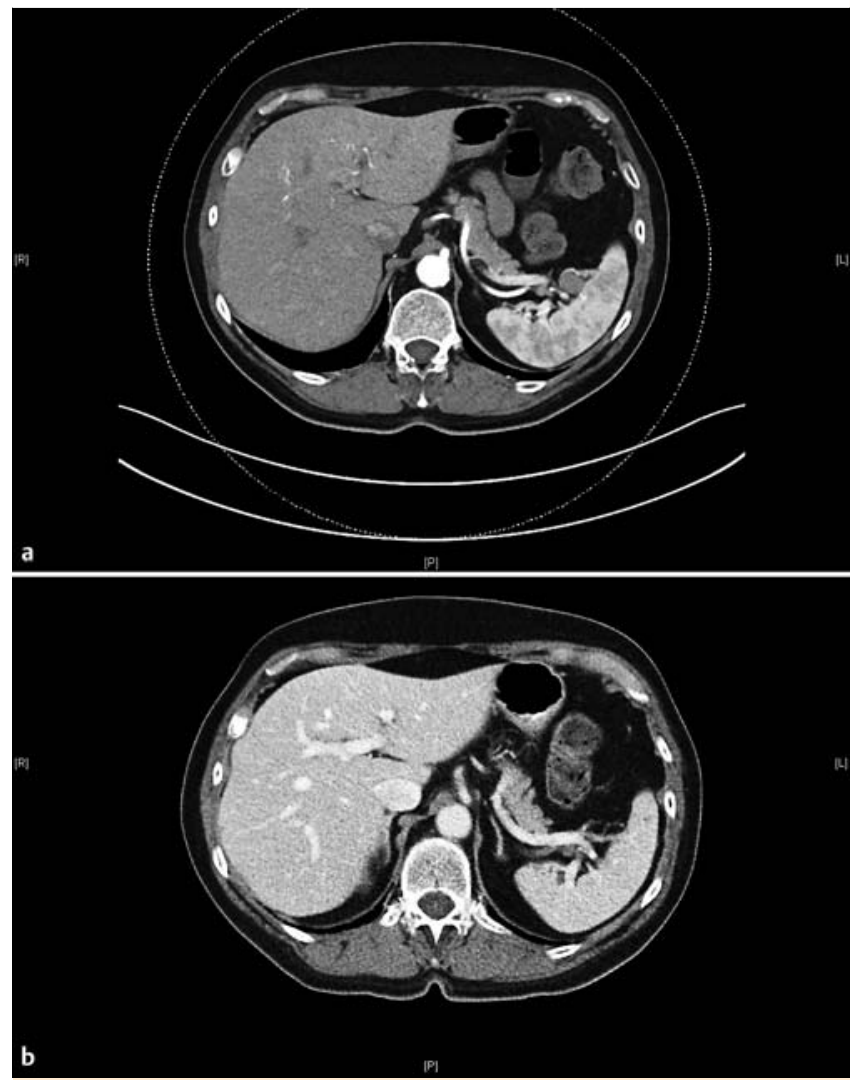

Abb.32 a CT vorher: CT-Aufnahme mit ausgeprägter Metastasierung der lienalen LK. b CT nachher: CT-Aufnahme nach Behandlung mit Pembrolizumab - die Filiarisierung der LK ist nicht mehr nachweisbar.

Diagnostik: Im Januar 2014 wurde im Rahmen der Routinenachsorge eine ausgeprägte Fernmetastasierung mit Lungen-, Milz- und Lebermetastasen, retroperitonealen und iliakalen LKFiliae sowie kutanen und intramuskulären Metastasen diagnostiziert. Eine durchgeführte Mutationsanalyse zur genaueren Planung einer Systemtherapie zeigte einen Wildtyp für BRAF, NRAS und cKIT.

Therapie und Verlauf: Wir begannen eine leitliniengerechte Tumortherapie mit Ipilimumab $3 \mathrm{mg} / \mathrm{kg}$ KG im Abstand von drei Wochen über insgesamt vier Gaben. Im folgenden Staging zeigten sich größtenteils regrediente Metastasen, mit Ausnahme einer neu aufgetretenen Raumforderung infrarenal, die im Juni 2014 mittels CyberKnife behandelt wurde. Eine im September 2014 aufgefallene intraorbitale Metastase links wurde gleichfalls mittels CyberKnife erfolgreich therapiert. Aufgrund weiterhin bestehenden Lymphknotenmetastasen iliakal und paraaortal wurde eine Therapie mit dem Anti-PD1-Antikörper Pembrolizumab $2 \mathrm{mg} / \mathrm{kg} \mathrm{KG}$ alle drei Wochen im Dezember 2014 initiiert. Im März 2015 zeigte sich daraufhin zunächst ein partielles Ansprechen mit regredienten Metastasen. Ausnahme bildete eine Lymphknotenmetastase inguinal links und eine kleine subkutane Metastase. Die progredienten Metastasen wurden chirurgisch in toto exzidiert. Mit dem gewonnenen Gewebe wurde nun eine dendritische Zellvakzinierung zusätzlich zur weitergeführten Pembrolizumab-Therapie initiiert. Im September 2015 zeigt sich im radiologischen Staging nun ein hervorragendes Ansprechen unter Pembrolizumab mit vollständig regredienten Metastasen (complete response) im kompletten Organismus ( $\mathbf{A b b}$.32a, 
und b). Die Therapie wurde von der Patientin ohne Nebenwirkungen sehr gut vertragen.

Kommentar: Schleimhautmelanome sind sehr selten - betroffene Patienten haben häufig aufgrund der späten Diagnosestellung eine schlechte Prognose. Veröffentlichungen zeigen, dass Patienten mit metastasierten Schleimhautmelanomen ein dauerhaftes Ansprechen auf Ipilimumab aufweisen können. Das Gesamtansprechen zeigt sich jedoch im Vergleich zum kutanen metastasierten Melanom bei gleichem Nebenwirkungsprofil wesentlich niedriger. Das mediane Gesamtüberleben bei Therapie des Schleimhautmelanoms mit Ipilimumab zeigt sich bei lediglich 6,4 Monaten im Vergleich zu 10,1 Monaten beim kutanen Melanom. Die Overall-Response-Rate auf Ipilimumab liegt beim Schleimhautmelanom bei 6,7\%, im Vergleich zu 10,9\% beim kutanen metastasierten Melanom. Ein Fallbericht zeigte ein Ansprechen auf PD-1-Antikörpertherapie nach Ipilimumab mit starken Nebenwirkungen. Trotzdem lohnt es sich, bei fehlenden anderen Alternativen einen Versuch der Therapie zu starten, wie der vorliegende Fall zeigt. Zu Kombinationstherapien von Pembrolizumab und dendritischer Zellimpfung liegen bisher noch keine Daten vor, jedoch lässt unser Fall auf eine additive Wirkung dieser beiden Therapien hoffen.

\section{Literatur}

1 Postow MA, Luke JJ, Bluth MJ et al. Ipilimumab for patients with Advanced Mucosal Melanoma. The Oncologist 2013; 18: 726-732

2 Hodi FS, O'Day SJ, McDermott DF et al. Improved survival with ipilimumab in patients with metastatic melanoma. N Engl J Med 2010; 363: $711-723$

3 Min l, Hodi FS. Anti-PD1 Following Ipilimumab for Mucosal Melanoma: Durable Tumor Response Associated with Severe Hypothyroidism and Rhabdomyolysis. Immunol Res 2013; 2: 15-18

\section{Therapierefraktärer Lichen ruber planopilaris am Kapillitium}

\section{G. Hauck}

Anamnese: Seit 2013 berichtete ein 31-jähriger Mann über progredienten Haarausfall am zentralen Kapillitium. Initial wurde bei dem Patienten eine androgene Alopezie diagnostiziert. Lokale Vortherapien mit verschiedenen Steroiden über mehrere Monate zeigten keine wesentliche Verbesserung des Befundes.

Untersuchungsbefund: Es zeigt sich am hochparietalen Kapillitium ein etwa $7 \times 5 \mathrm{~cm}$ großes, mild erythematöses, zentral atrophes, haarloses Areal. Zum Rand des Areals findet man wieder vermehrt dichter stehende Haare $(\bullet$ Abb. 33).

Diagnostik: In einer Probebiopsie waren die zur Darstellung kommenden Haaradnexe entzündlich verändert, im oberen Drittel zeigt sich eine lymphozytäre perifollikuläre Entzündungsreaktion. Auffällig war zudem das vollständige Fehlen der Talgdrüsen. Die zur Darstellung kommenden Haarschäfte zeigten eine Trichomalazie. In der Beurteilung zeigte sich eine lymphozytäre Entzündungsreaktion im oberen Follikeldrittel. Durch diese Probebiopsie konnte als Ursache der vernarbenden Alopezie ein Lichen ruber planopilaris diagnostiziert werden. Typisch ist hier das Fehlen der Talgdrüsen und die lymphozytäre perifollikuläre Entzündungsreaktion. Häufig sieht man auch eine vakuoläre Degeneration der basalen und adnexiellen Keratinozyten.

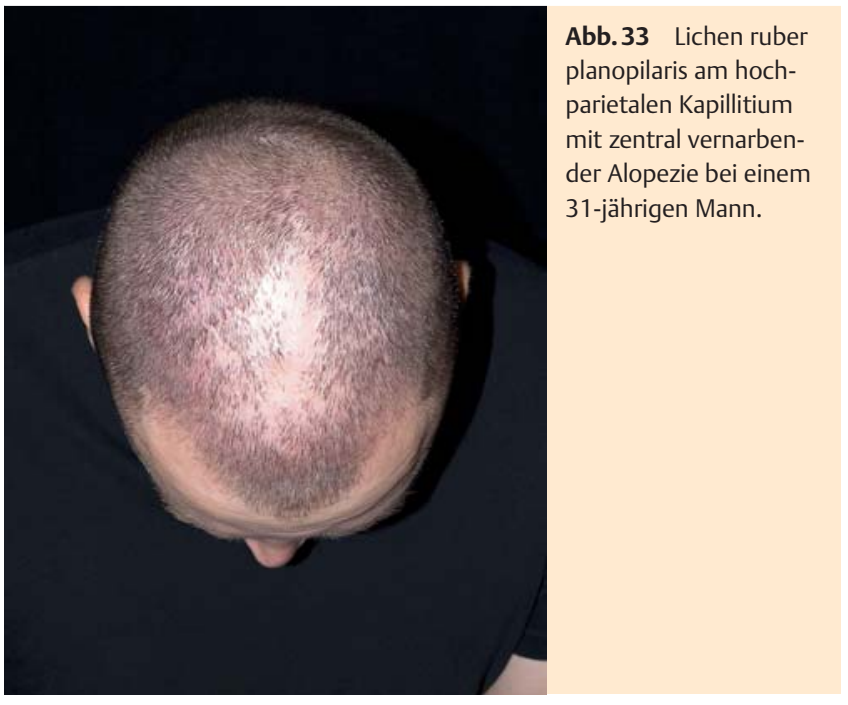

Therapie und Verlauf: Es erfolgte zunächst eine Therapie mit Resochin $250 \mathrm{mg} 1 \times \operatorname{tgl}$. mit unterstützender Lokaltherapie mittels Mometason-Lösung. Aufgrund des für den Patienten unzureichenden Therapieerfolgs wurde die Lokaltherapie auf Clobetason-Lösung umgestellt. Kurzfristig wurde additiv Urbason $40 \mathrm{mg} / \mathrm{d}$ über vier Wochen ausschleichend hinzugegeben. Nach beginnender Verbesserung des Befundes konnte auf eine alleinige Erhaltungstherapie mit Resochin $250 \mathrm{mg} 1-0-0$, Resochin junior $0-0-1 / 2$ und Clobetason-Lösung $2 \times /$ Woche umgestellt werden, was zu einem anhaltenden, zufriedenstellenden Ergebnis führte.

Kommentar: Bei der Erkrankung des Patienten handelt es sich um eine Sonderform des Lichen ruber, die sich durch eine chronische, an die Haarfollikel gebundene, primär lymphozytäre Follikulitis auszeichnet. Diese führt zu einer schleichenden Follikelatrophie, was wiederum klinisch in einer Alopezie mündet. Die Erkrankung tritt im mittleren Lebensalter auf und betrifft häufiger Frauen. Die Ätiologie ist bis heute nicht hinreichend geklärt. Die Erkrankung gilt als äußerst therapierefraktär. Eine mögliche Behandlung kann mit Cyclosporin-A durchgeführt werden. Gute klinische Resultate wurden beim Einsatz von Hydroxychloroquin und oralen Retinoiden beschrieben. Eine Therapie mit Resochin zeigte in einer Studie mit 40 Patienten eine Befundbesserung bei $83 \%$. Auch bei unserem Patienten zeigte sich die Therapie erfolgreich. In der Literatur sind ebenfalls erfolgreiche Ansätze mit Adalimumab zur Therapie des Lichen planopilaris beschrieben. In sehr seltenen Fällen kann der Lichen planopilaris zu einem kutanen Plattenepithelkarzinom transformieren.

\section{Literatur}

1 Baibergenova A, Donovan J. Lichen planopilaris: update on pathogenesis and treatment. Skinmed 2013; 11: $161-165$

2 Chieregato C, Zini A, Barba A et al. Lichen planopilaris: report of 30 cases and review of the literature. Int J Dermatol 2003; 42: 342-345

3 Mirmirani P, Willey A, Price VH. Short course of oral cyclosporine in lichen planopilaris. J Am Acad Dermatol 2003; 49: 667-671

4 Chiang C, Sah D, Cho BK et al. Hydroxychloroquine and lichen planopilaris: efficacy and introduction of Lichen Planopilaris Activity Index scoring system. J Am Acad Dermatol 2010; 62: 387-392

4 Kreutzer $K$, Effendy I. Therapy-resistant folliculitis decalvans and lichen planopilaris successfully treated with adalimumab. J Dtsch Dermatol Ges 2014;1 2: 74-76 


\section{Symmetrisch geschwollene Mamillen bei einem jungen Mann $\nabla$}

\section{P. Kleimann}

Anamnese: Die Vorstellung des 17-jährigen Patienten erfolgte aufgrund von seit mehreren Monaten bestehenden geschwollenen Brustwarzen. Er gab keine Schmerzen oder weitere Beschwerden an, empfand den Befund jedoch als kosmetisch sehr störend. Der Patient nahm keine Medikamente ein, Grunderkrankungen waren ebenfalls nicht bekannt.

Untersuchungsbefund: Es zeigte sich eine beidseitige, symmetrische Schwellung der Mamillen und der umgebenden Haut und Unterhaut ( $\bullet$ Abb.34). Bei Palpation konnten keine Vergrößerung des Brustdrüsenkörpers oder andere Resistenzen getastet werden. Eine Pseudogynäkomastie konnte bei dem sonst schlanken Patienten ebenfalls ausgeschlossen werden. Der restliche Hautbefund war altersentsprechend unauffällig.

Verlauf: Eine sonografische Untersuchung in der Gynäkologie bestätigte, dass die Schwellung nicht mit einer Vergrößerung des Brustdrüsenkörpers einherging. Zum Ausschluss einer hormonellen Veränderung erfolgte eine Bestimmung des Testosteron, LH, FSH, Prolaktin, Estradiol, des freien Androgenindex, SHBG, DHEAS und Androstendion im Serum - diese waren allesamt normwertig.

Da sich keinerlei Hinweise auf ein malignes Geschehen oder eine hormonelle Störung ergaben, entschlossen wir uns in Absprache mit dem Patienten, lediglich klinische Kontrollen durchzuführen. Kommentar: In der Literatur finden sich so gut wie keine Berichte über eine beidseitige Mamillenvergrößerung ohne Beteiligung des Brustdrüsengewebes bei männlichen Patienten. Abzugrenzen ist hier die harmlose und relativ häufige Pubertätsgynäkomastie, die jedoch im Normalfall den Brustdrüsenkörper miteinschließt.

Bei vergrößerten Mamillen bzw. Gynäkomastie bei Männern sollte prinzipiell immer eine Untersuchung der Hormonachse erfolgen. Mögliche hormonelle Ursachen sind z.B. Hypogonadismus, östrogenproduzierende Hodentumore, Adenome der Hypophyse oder des Hypothalamus, Substitution von Testosteron (z. B. Anabolika) sowie eine ausgeprägte Leber- oder Niereninsuffizienz. Weiterhin muss auch an hereditäre Ursachen wie zum Beispiel das Klinefelter-Syndrom gedacht werden. Auch wenn beidseitige Malignome des Brustdrüsengewebes selten sind, werden

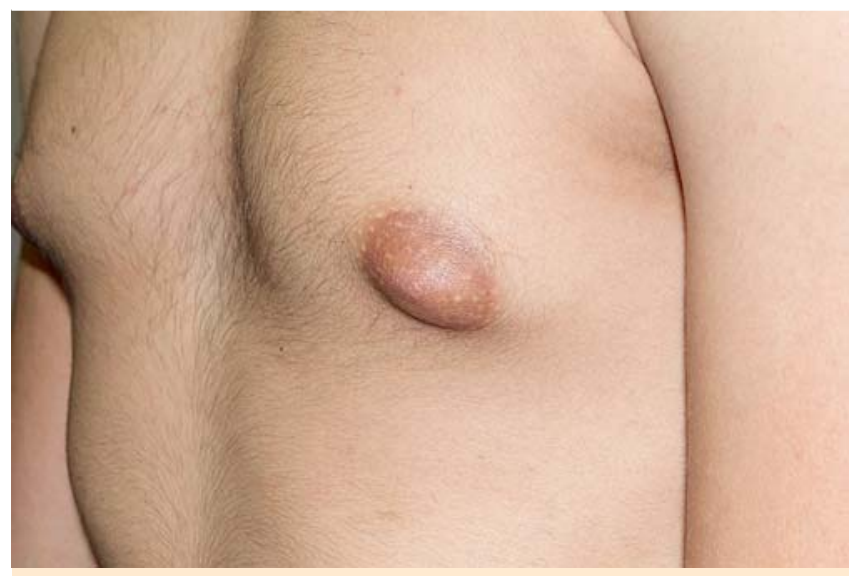

Abb.34 Symmetrische Schwellung beider Mamillen ohne Beteiligung des Brustdrüsengewebes eines 17-jährigen Jungen. in der Fachliteratur einige Fälle beschrieben. Daher sollte auch bei beidseitiger Schwellung der Mamillen bzw. Gynäkomastie immer an ein Malignom gedacht bzw. dies durch geeignete Untersuchungen wie Ultraschall oder Feinnadelpunktion ausgeschlossen werden.

Bei kosmetisch stark störendem Befund gibt es die Möglichkeit einer chirurgischen Entfernung des überschüssigen Binde- und Fettgewebes, z.B. mittels Liposuktion. Da dies jedoch invasivere chirurgische Eingriffe unter Vollnarkose bedeutet, die auch mit postoperativen Komplikationen einhergehen können, stellt das Abwarten in den meisten Fällen die bessere Alternative dar. Mit Verlaufskontrollen war der Patient ebenfalls einverstanden.

\section{Literatur}

1 Rubio Hernandez MC, Diaz Prado YI, Rodriguez Perez S et al. Synchronous bilateral breast cancer in a male. Ecancermedicalscience 2013; 4: 377

2 Lemoine C, Mayer SK, Beaunoyer M et al. Incidental finding of synchronous bilateral ductal carcinoma in situ associated with gynecomastia in a 15-year-old obese boy: case report and review of literature. J Pediatr Surg 2011; 46 (9): e17-20

3 Abaci A, Buyukgebiz A. Gynecomastia: review. Pediatric Endocrinology Reviews 2007; 5: 489-499

\section{Kutane Manifestation einer Sarkoidose - ein seltenes dermatologisches Erkrankungsbild $\nabla$ \\ F. Pfeifer}

Anamnese: Ein 42-jähriger Patient berichtete über seit zwei Jahren bestehende, asymptomatische Hautveränderungen im Bereich der Kopfhaut, der Schläfen und des Rückens. Des Weiteren gab der Patient an, seit etwa 6-9 Monaten an Gliederschmerzen und allgemeiner Abgeschlagenheit zu leiden. Vortherapien seien bislang lediglich mit topischen Steroiden erfolgt. Bis auf eine Rhinokonjunktivitis allergica waren keine weiteren Grunderkrankungen bekannt. Medikamente wurden von dem Patienten zum Zeitpunkt der Erstvorstellung nicht eingenommen.

Befund: Es fanden sich am oberen Rücken, den Oberarmen sowie an den Unterschenkeln streckseitig kleinknotige, erythematöse, runde, $2-3 \mathrm{~cm}$ durchmessende Plaques mit betont gelblichen Rändern ( $\bullet$ Abb.35). Diaskopisch zeigte sich darüber hinaus ein lupoides Infiltrat. Am Kapillitium fanden sich zusätzlich hochfrontal bis okzipital gelegene, multiple, rotbraune, runde Plaques mit ebenfalls gelblichen Rändern, die zentral zu einem handtellergroßen Plaque konfluieren ( $\bullet$ Abb.36).

Diagnostik: Im histologischen Präparat zeigte sich eine Epidermis mit minimaler Hyperkeratose und leichter Spongiose. Subepidermal fanden sich zahlreiche Granulome, bestehend aus Epitheloid- und Riesenzellen, jedoch kein Nachweis von Verkäsung. Zum Ausschluss von Fremdorganismen wurde eine PAS-Färbung angefertigt, diese blieb ohne wegweisenden Befund. Zusammenfassend zeigte die Hautbiopsie das Bild einer granulomatösen Dermatitis, vereinbar mit einer kutanen Manifestation einer Sarkoidose ( Abb.37). Eine bildgebende Diagnostik mittels Röntgen-Thorax und Sono-Abdomen zum Ausschluss einer weiteren Organmanifestation der Sarkoidose blieb ohne wegweisenden Befund. Des Weiteren wurde eine laborchemische Diagnostik durchgeführt. Hier zeigten sich, passend zur Diagnose, der ACEWert im Serum mit 110U/L erhöht, ein positiver ANA-Titer bei $1: 320$ sowie ein erhöhter Wert für IL-2 R mit 1753U/L. DNS-AK und ENA-Screen waren negativ. Ein HIV-Test zum Ausschluss 


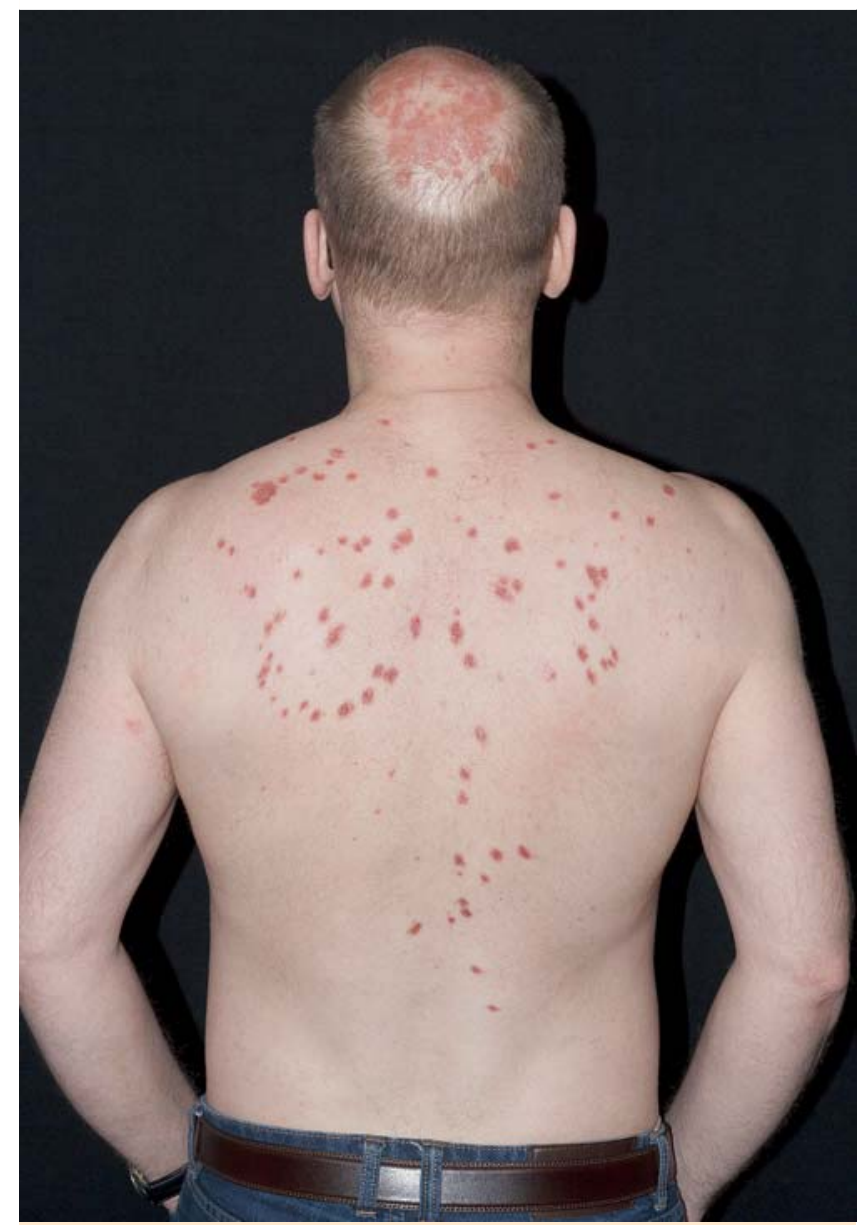

Abb.35 Sarkoidose Rücken.

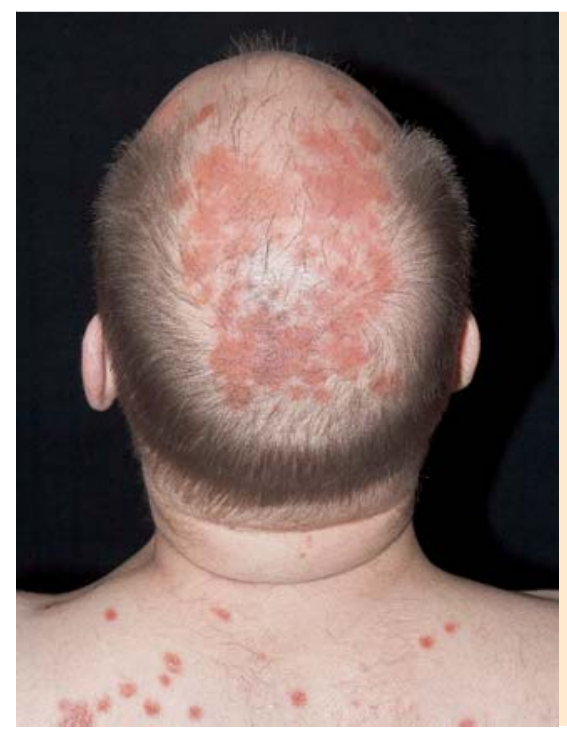

Abb.36 Sarkoidose Kopf: Disseminiert stehende erythematöse Papeln am oberen Rücken sowie konfluierend am zentralen Kapillitium.

von „sarcoid like lesions“ sowie bei persistierender Abgeschlagenheit und Gliederschmerzen war ebenfalls negativ.

Therapie und Verlauf: Intial erfolgte eine Lokaltherapie mit 0,1\% Betamethason-Creme an Stamm und Extremitäten sowie Prednicarbat-Creme für das Kapillitium und das Gesicht. Unter der Lokaltherapie persistierte der Hautbefund, sodass eine Systemtherapie mit $250 \mathrm{mg}$ Chloroquin eingeleitet wurde, die im weite-

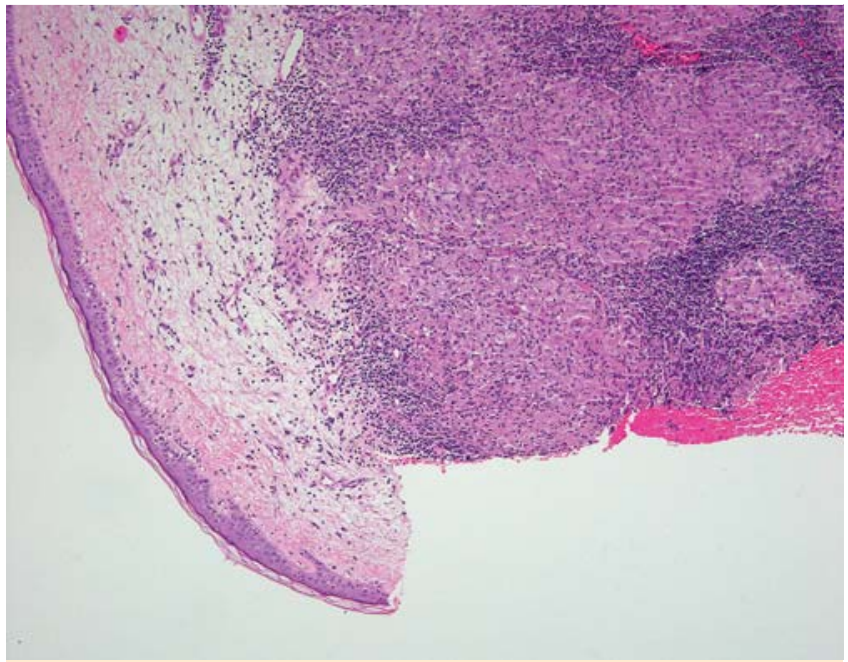

Abb.37 Histologie: Subepidermale, multiple, nicht verkäsende Granulome aus Epitheloidzellen und Riesenzellen (HE 100×).

ren Verlauf zwar protrahiert aber stetig eine Befundbesserung erbrachte.

Kommentar: Die Sarkoidose ist eine seltene Multisystemerkrankung mit einem Häufigkeitsgipfel zwischen den 20. - 40. Lebensjahr unklarer Genese. Das Risiko zu erkranken erhöht sich bei einer positiven Familienanamnese sowie einer Genmutation für BTNL2 (Chromosom 6). Primär ist diese Erkrankung mit erhöhten Werten für Interferon-gamma, IL-2 und IL-12 vergesellschaftet. Charakteristisch in der Histologie, jedoch nicht für eine Sarkoidose spezifisch, sind nicht-verkäsende, epitheloidzellige Granulome mit Langerhans- und Riesenzellen sowie ein Lymphozytensaum. Zudem lassen sich Schaumann-Körper (Protein-Körper) sowie Asteroid-Körper im histologischen Präparat finden. Als Differenzialdiagnosen basierend auf der Histologie sind „sarcoid like lesions“ bei einer HIV-Infektion oder tuberkulöse Granulome zu sehen.

Es zeigt sich in 30\% der Fälle eine kutane Manifestation. Hier finden sich verschiedene Unterformen. Man unterscheidet eine kleinknotig-disseminierte Form, eine großknotige Form, eine anuläre oder zirzinäre Form sowie eine kutan-knotige Form wie im vorliegenden Fallbeispiel. Sonderfomen bilden der Lupus pernio und die Narbensarkoidose.

Die Therapie der Sarkoidose richtet sich nach der Klinik und dem Organbefall. Die Indikation für eine Systemtherapie ist bei der kutanen Sarkoidose eng zu stellen.

Neben der Therapie mit lokalen Steroiden sind bei protrahierten Verläufen interne Steroide, Azathioprin, Methotrexat sowie Chloroquin als Systemtherapie in Erwägung zu ziehen. Einzelne Fallberichte zeigen eine erfolgreiche Therapie mit intralesionaler Injektion von 5-FU bei lokal begrenzter Manifestation.

\section{Literatur}

1 Sanchez M, Haimoviv A, Prystowsky S. Sarcoidosis. Dermatol Clin 2015; 33: $389-416$

2 Gharavi N, Diehl J, Soriano T. Cutaneous Sarcoidosis sucessfully treated with intralesional 5-Fluoruracil. Dermatol Surg 2015; 41: 1082-1085 
Livide retikuläre Erytheme, Fieberschübe und unklarer Husten - Reaktive Angioendotheliomatose bei einer Patientin mit Pneumonie $\nabla$

\section{K. Schultheis}

Anamnese: Wir berichten von einer 76-jährigen Patientin mit, seit zirka einem halben Jahr bestehenden, rezidivierenden, unklaren Fieberschüben, trockenem Husten und Gewichtsverlust. An der Haut zeigten sich zudem unklare livide Erytheme.

Befund: Die körperliche Untersuchung zeigte leicht geschwollene zervikale Lymphknoten. Am Stamm und an den Extremitäten zeigten sich zusätzlich flächenhafte, unscharf begrenzte, asymptomatische, wegdrückbare, livid-rot-retikuläre Erytheme

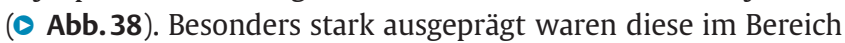
der linken Brust. Im Labor zeigten sich leicht erhöhte Entzündungswerte und eine milde Thrombozytopenie.

Histologie: Die Histologie wies eine intravaskuläre, überwiegend lymphozytäre Entzündungsreaktion nach. Weiter zeigten sich intravaskuläre, schaumige Makrophagen, welche die Lumen okkludieren, zur Rekanalisation und immer wieder zu Hämorrhagien führten. Es konnte somit histologisch eine Vaskulitis im Sinne einer reaktiven Angioendotheliomatose gesichert werden (॰ Abb.39).

Therapie und Verlauf: Es erfolgte eine intensivierte Abklärung bei unklarem Fieber und Husten inklusive bronchioalveolärer Lavage zum Ausschluss einer Tuberkuloseinfektion. Diese konnte mittels Quantiferontest und Kultur aber ausgeschlossen werden. Jedoch zeigte die Kultur den Nachweis von Enterococcae cloacae. Somit wurde die Patientin bei diagnostizierter Pneumonie antibiogrammgerecht mittels Imipinem $2 \mathrm{~g} / \mathrm{d}$ behandelt. Hierunter deutliche Verbesserung der Klinik, Anstieg der Thrombozytenwerte und Abblassung der Erytheme innerhalb der ersten Wochen.

Kommentar: Bei der Angioendotheliomatose muss die maligne von der benignen (reaktiven) Form abgegrenzt werden. Bei der selteneren benignen Form ist die Erkrankung ausschließlich auf die Haut begrenzt. Histologisch ist sie durch eine Endothelzellproliferation gekennzeichnet. Als Ursache werden verschiedene Systemerkrankungen (am häufigsten Endokarditis, aber auch Paraneoplasien) angesehen. Hierdurch kommt es zur Freisetzung von proangiogenen Faktoren und somit zu einer Endothelzellhyperplasie und Bildung von Mikrothromben. Durch Behandlung der Systemerkrankung bildet sich die reaktive Form zurück.

Die maligne Form ist häufiger. Sie wird als intravaskuläre Form eines Lymphoms, häufig eines B-Zell-Lymphoms, angesehen. Histologisch erkennt man intravasale atypische Lymphozyten. Klinisch sind auch andere Organe als die Haut betroffen. Immer ist eine Beteiligung des zentralen Nervensystems vorhanden, ein Befall jedes anderen Organs ist möglich und die Klinik ist hier sehr variabel. Sie endet häufig rasch letal. Chemotherapien sind wenig erfolgversprechend.

Bei unserer Patientin spricht das Fehlen sowohl von einer neurologischen Symtomatik als auch der atypischen Lymphozyten bei eindeutiger Histologie für das Vorliegen einer reaktiven, benignen Angioendotheliomatose. Da sich die Hauterscheinungen unter der Antibiose rasch besserten, kann als Ursache der Angioendotheliomatose von der Pneumonie durch Enterococcae cloacae ausgegangen werden.

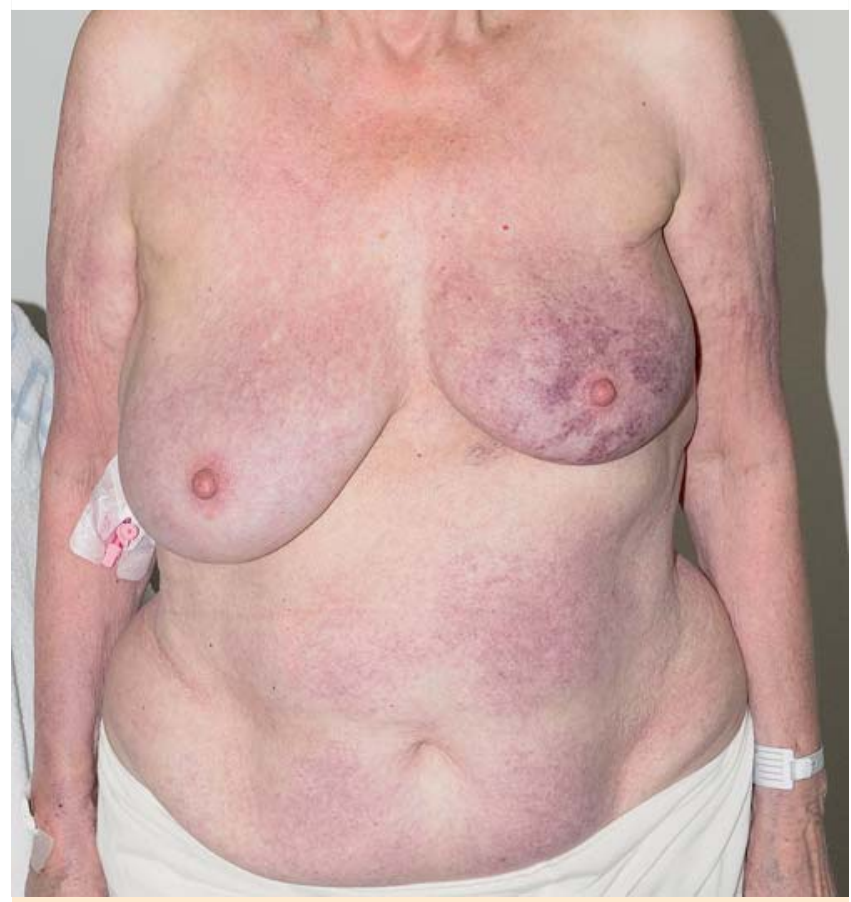

Abb.38 Angioendotheliomatose: Flächenhafte livid-rot-retikuläre Erytheme am Stamm mit Betonung der linken Mamma.

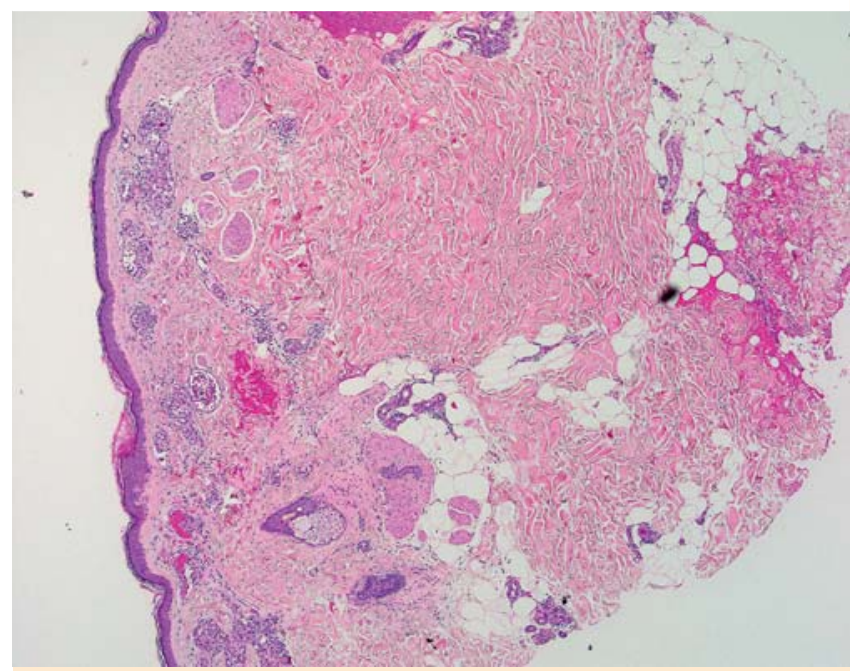

Abb.39 Angioendotheliomatose - Histologie: Charakteristisch finden sich bei der Angioendotheliomatose intravaskuläre schaumige Makrophagen mit Okklusion und Rekanalisation der dermalen Gefäße sowie ein perivaskuläres lymphozytäres Infiltrat (HE 40×).

\section{Literatur}

1 Schmidt K, Harting C, Stadler R. Reaktive Angioendotheliomatose bei chronisch lymphatischer Leukämie. Hautarzt 1996; 47: 550-555

2 Liszka U, Drlicek M, Hitzenberger P et al. Intravascular lymphomatosis: a clinicopathological study of three cases. J Cancer Res Clin Oncol 1994; 120: $164-168$

3 Wallenfang K, Stadler R. Angioendotheliomatose - Eine Literaturübersicht. Akt Dermatol 2002; 28: 374-379

\section{Interessenkonflikt}

$\nabla$

Die Autoren geben an, dass kein Interessenkonflikt besteht. 